\title{
1 Tau modulates mRNA transcription, alternative 2 polyadenylation profiles of hnRNPs, chromatin remodeling 3 and spliceosome complexes
}

4

\author{
Montalbano Mauro ${ }^{1,2}$, Elizabeth Jaworski ${ }^{3}$, Stephanie Garcia ${ }^{1,2}$, Anna Ellsworth ${ }^{1,2}$, \\ Salome McAllen ${ }^{1,2}$, Andrew Routh ${ }^{3,4}$ and Rakez Kayed ${ }^{1,2}+$. \\ ${ }^{1}$ Mitchell Center for Neurodegenerative Diseases, University of Texas Medical Branch, Galveston, Texas, \\ 77555 , USA \\ 2 Departments of Neurology, Neuroscience and Cell Biology, University of Texas Medical Branch, \\ Galveston, Texas, 77555 , USA \\ ${ }^{3}$ Department of Biochemistry and Molecular Biology, University of Texas Medical Branch, Galveston, Texas \\ 77555, USA \\ ${ }^{4}$ Sealy Center for Structural Biology and Molecular Biophysics, University of Texas Medical Branch, \\ Galveston, TX, USA \\ † To whom correspondence should be addressed
}

\section{Corresponding Author}

Rakez Kayed, PhD

University of Texas Medical Branch

Medical Research Building Room 10.138C

301 University Blvd

Galveston, TX 77555-1045

Phone: 409.772 .0138

Fax: 409.747.0015

e-mail: rakayed@utmb.edu

Running Title: Tau modulates transcription and alternative polyadenilation processes

Keywords: Tau, Transcriptomic, Alternative Polyadenilation, Nuclear Dysfunction, Neurodegeneration

\section{Conflict of Interest: None}

Abbreviations: AD, Alzheimer's disease; APA, alternative polyadenylation; DDR, DNA damage response; FTD, frontal temporal dementia; GO, Gene Ontology; GSEA, gene set enrichment analysis; GWAS, genome wide association study; MTs, microtubules; PAC, poly(A) cluster; PACSeq; Poly(A)-ClickSeq, PAP, poly-A polymerase; PAS, poly(A) site; RNA, ribonucleotide acid; Tet, Tetracycline; 3'UTR, 3' untranslated region; iHEK, inducible human embryonic kidney cells; ER, endoplasmic reticulum; 


\section{Author summary}

47 While tau biology has been extensively studied and closely linked to several neurodegenerative 48 diseases, our current understanding of tau's functions in the nucleus is limited. Given the role of 49 tau in disease progression and pathogenesis, elucidating the function of tau activity in 50 transcription and its nuclear accumulation may reveal novel therapeutic targets; therefore, helping

51 identify new upstream pathways that have yet to be investigated. In this study, we used tau-

52 inducible cell lines to uncover new molecular mechanisms by which tau functions in the nucleus.

53 This study systematically investigates the changes in transcriptomic and alternative

54 polyadenylation profiles modulated by WT and mutant P301L tau protein. In this manuscript, we

55 report following new findings (i) tau modulates gene expression of transcripts associated with

56 chromatin remodeling and splicing complexes; (ii) WT and mutant P301L tau regulate,

57 differentially, transcription and alternative polyadenylation (APA) profiles; and (iii) P301L mutation

58 affects the transcription mediated by tau protein._The potential role of tau in mediating

59 transcription and alternative polyadenylation processes is not well studied, representing a novelty

60 in the field. Therefore, this research establishes a new direction for investigating tau nuclear

61 function in both human and mouse brains.

62

63

64

65

66

67

68

69

70

71

72

73

74

75

76

77

78 

during early phases of pathogenesis.

\section{Abstract}

Tau protein is a known contributor in several neurodegenerative diseases, including Alzheimer's disease (AD) and frontotemporal dementia (FTD). It is well-established that tau forms pathological aggregates and fibrils in these diseases. Tau has been observed within the nuclei of neurons, but there is a gap in understanding regarding the mechanism by which tau modulates transcription. We are interested in the P301L mutation of tau, which has been associated with FTD and increased tau aggregation. Our study utilized tau-inducible HEK (iHEK) cells to reveal that WT and P301L tau distinctively alter the transcription and alternative polyadenylation (APA) profiles of numerous nuclear precursors mRNAs, which then translate to form proteins involved in chromatin remodeling and splicing. We isolated total mRNA before and after over-expressing tau and then performed Poly(A)-ClickSeq (PAC-Seq) to characterize mRNA expression and APA profiles. We characterized changes in Gene Ontology (GO) pathways using EnrichR and Gene Set Enrichment Analysis (GSEA). We observed that P301L tau up-regulates genes associated with reactive oxygen species responsiveness as well as genes involved in dendrite, microtubule, and nuclear body/speckle formation. The number of genes regulated by WT tau is greater than the mutant form, which indicates that the P301L mutation causes loss-of-function at the transcriptional level. WT tau up-regulates genes contributing to cytoskeleton-dependent intracellular transport, microglial activation, microtubule and nuclear chromatin organization, formation of nuclear bodies and speckles. Interestingly, both WT and P301L tau commonly downregulate genes responsible for ubiquitin-proteosome system. In addition, WT tau significantly down-regulates several genes implicated in chromatin remodeling and nucleosome organization. Although there are limitations inherent to the model systems used, this study will improve understanding regarding the nuclear impact of tau at the transcriptional and post-transcriptional level. This study also illustrates the potential impact of P301L tau on the human brain genome 


\section{Introduction}

107 Tau is a neuronal protein found both inside and outside of the nucleus that contributes to the 108 pathology of neurodegenerative diseases such as frontotemporal dementia (FTD) and 109 Alzheimer's disease $(A D)^{1}$. It is primarily described as a microtubule-associated protein ${ }^{2}$. Nuclear 110 tau has been found to 'protect' DNA ${ }^{1-3}$ during reactive oxygen species (ROS)-induced heat stress.

111 However, nuclear and cytosolic tau interact with RNA to form droplets ${ }^{4}$ and aggregates ${ }^{5}$. Tau has

112 also been observed altering nuclear structure ${ }^{6,7}$ in the human nuclei of neuroblastoma ${ }^{8,9}$ and in

113 HEK-293 cells. More specifically, phosphorylation of nuclear tau negatively regulates its nuclear

114 function in pluripotent neuronal cells and neuroblastoma cells $\mathbf{s}^{10}$. Previous studies have revealed

115 that nuclear tau plays a role in the DNA damage response (DDR) through deadenylation, which 116 triggers major mRNA decay pathways ${ }^{11,12}$. Most recently, we found that oligomeric assemblies of

117 tau containing RNA-binding proteins impair chromatin remodeling and nuclear lamina formation 118 through associations with histones and chromatin components in the nuclear compartment ${ }^{13}$.

Despite the well-established importance of tau in the cytoskeleton of neurons ${ }^{14}$, there is 120 growing evidence that tau is notably involved in nucleolar transcription and cellular stress 121 responses ${ }^{15,16}$. Recently, it was shown that mutations and/or the phosphorylation of tau results in

122 the deformation of the neuronal nuclear membrane and can disrupt nucleocytoplasmic transport ${ }^{17}$ 123 in $\mathrm{FTD}^{7,18}$ and $\mathrm{AD}^{19,20}$. Related studies analyzed the direct impact in transcriptional activity due to

124 tau and found that nuclear tau regulates the expression of VGluT1, a gene that controls 125 glutamatergic synaptic transmission, and that tau displacement from microtubules (MTs) 126 increases nuclear accumulation of tau ${ }^{21}$. Furthermore, tau modifies histone acetylation and was

127 shown to have a broad epigenomic impact in the aging and pathology of AD human brains ${ }^{22}$. It 128 has also been observed that tau interacts with neuronal pericentromeric DNA regions, particularly 129 in association with HP1 and $\mathrm{H} 3 \mathrm{~K} 9 \mathrm{me} 3^{23}$, this observation spots tau protein as potential chromatin 130 remodeling factor. Lastly, tau exhibits binding interactions with genic and intergenic DNA 
131 sequences of primary cultured neurons, especially in positions \pm 5000 bp away from the start site

132 of transcription ${ }^{24}$.

133 In eukaryotic cells, the maturation of 3' ends in mRNA involves endonucleolytic cleavage

134 of the nascent RNA followed by the synthesis of a poly $(\mathrm{A})$ tail on the 3 ' terminus of the cleaved

135 product by a poly $(\mathrm{A})$ polymerase $(\mathrm{PAP})^{25}$. This reaction is called polyadenylation and is

136 fundamentally linked to transcription termination. The sequences for the mRNA precursors and

137 the proteins required for polyadenylation are well understood. It has been clearly elucidated that

138 a single gene can give rise to many possible transcripts, each with different polyadenylation sites

139 (poly(A)-sites, or PASs), and that differential usage of these sites can lead to the formation of

$140 \mathrm{mRNA}$ isoforms. This phenomenon is called alternative polyadenylation (APA) ${ }^{26}$ and is a common

141 event in eukaryotic cells. In fact, researchers have determined that $50 \%$ of mammalian mRNA-

142 encoding genes express APA isoforms ${ }^{27,28}$. Considering this information, we used tau inducible

143 HEK (iHEK) cell lines to obtain and analyze transcriptomic and APA profiles in the presence of

144 WT and P301L tau. To characterize transcriptional and post-transcriptional profiles modified by

145 WT and P301L, we utilized Poly(A)-ClickSeq (PAC-Seq) to measure changes in the expression

146 of the host mRNA transcript whilst simultaneously characterizing changes in the PAS usage or

147 creation of mRNA isoforms. In addition, we employed Gene Set Enrichment Analysis (GSEA) and

148 Gene Ontology (GO) to study the main gene domains modulated by tau. 


\section{Materials and Methods}

157 Cell Culture and Tau Expression. In this study we used two different versions of tau inducible 158 HEK (iHEK) cells: iHEK overexpressing WT tau and iHEK overexpressing mutated P301L tau. 159 They were maintained in Dulbecco's modified eagle medium (DMEM) supplemented with 10\% 160 fetal bovine serum (FBS) at $37{ }^{\circ} \mathrm{C}$ in $5 \% \mathrm{CO}_{2}$. To induce WT and mutant tau overexpression, 161 iHEK cells were treated with $1 \mu \mathrm{g} / \mathrm{mL}$ of Tetracycline (Tet) for 24 hours in FBS-depleted DMEM 162 (Gibco ${ }^{\mathrm{TM}}$ LS11965118, Fisher Scientific). iHEK cells not treated with Tet were named control (Ctr). After 24 hours, two washes with medium were done to remove excess Tet. Immediately after the washes, the cells were stained and collected. Detachment of cells was completed with Trypsin (Gibco ${ }^{\text {TM }}$ Trypsin-EDTA, 0.25\% Phenol red, LS25200114 Fisher Scientific), and the cells warmed for 3 minutes in the incubator following the addition of Trypsin. The cells were then centrifuged at 1000 rpm for 5 minutes. Lastly, cell pellets were harvested and used for protein fractionation, and mRNA extraction.

RNA Extraction. Total mRNA was collected by using TRIzol extraction reagent according to

171 established protocol ${ }^{29}$. RNA samples for Real Time Analysis (RT-PCR) were quantified using a

172 Nanodrop Spectrophotometer (Nanodrop Technologies), followed by analysis on an RNA Nano 173 chip using the Agilent 2100 Bioanalyzer (Agilent Technologies). Only samples with high quality 174 total RNA were used (RIN: 7.5-10.0) for the study. Synthesis of cDNA was performed with either $1750.5 \mu \mathrm{g}$ or $1 \mu \mathrm{g}$ of total RNA in a $20 \mu \mathrm{l}$ reaction using the reagents available within the Taqman 176 Reverse Transcription Reagents Kit from Life Technologies (\#N8080234). Q-PCR amplifications 177 (performed in duplicate or triplicate) were done using $1 \mu$ l of cDNA in a total volume of $20 \mu l$ using 178 the iTaq Universal SYBR Green Supermix (Bio-Rad \#1725125). The final concentrations of the 179 primers were 300nM. Relative RT-QPCR assays are performed with either 18S RNA gene as a 180 normalizer. Absolute RNA quantification analysis was performed using known amounts of a 181 synthetic transcript created from the gene of interest. 
Library Preparation Protocol. Protocols for Poly(A)-ClickSeq (PAC-Seq) have been described in detail by Jaworski et al. $2018^{30,31}$. Approximately $1 \mu \mathrm{g}$ of total cellular RNA per sample was used as a template in reverse-transcription reactions supplemented with 40uM Azido-VTPs and primed using an oligo-dT primer containing a partial Illumina i7 indexing adaptor. Azido-terminated cDNA fragments were 'click-ligated' to hexynyl-functionalized click-adaptors containing the Illumina i5 universal sequencing adaptor. Single-stranded cDNA libraries were indexed in a final PCR reaction for 15-18 PCR cycles. Final libraries were size extracted by gel-electrophoresis and submitted for sequencing using an Illumina NextSeq550 to prepare 1x150 SE reads. RNAseq datasets is uploaded to NCBI SRA, reference number: PRJNA744518. program, which ran with default settings as previously described ${ }^{32}$. DPAC trims and quality-filters raw FASTQ data and therefore requires each read to have at least 25 'As' at the 3 ' end of the read. These reads are then trimmed using cutadapt. Trimmed reads are mapped to the reference human genome (hg19) using HISAT2 ${ }^{33}$. The 3'end of mapped reads are thus used to annotate poly(A)-sites and annotated based upon overlaps with gene annotations obtained from UCSC genome browser. Gene counts were extracted and DESeq2 was used to calculated changes in gene expression as well as relative changes in expression in individual poly(A)-sites found within 201 single genes. Differential gene expression was assigned when a gene had a fold change greater 202 than $+/-1.5$-fold with a $p$-adj value less than 0.1 . Alternative polyadenylation is assigned when a 203 single gene has two or more clustered poly(A)-sites wherein at least one of these sites has a 204 differential usage greater than a $+/-1.5$-fold, a $p$-adj value less than 0.1 , and a change of the 205 relative usage of a poly(A)-cluster within the gene of greater than $10 \%$. 
Western Blotting and Cell Fractioning. Immunoblot (IB) analyses were performed with iHEK cell fraction samples as previously described ${ }^{13}$. Approximately $10 \mu \mathrm{g}$ of protein preparations were loaded onto precast NuPAGE 4-12\% Bis-Tris gels (NP0335BOX, Invitrogen) for sodium dodecyl sulfate-polyacrylamide gel electrophoresis (SDS-PAGE) analyses. Gels were subsequently

211 transferred onto nitrocellulose membranes and blocked overnight at $4^{\circ} \mathrm{C}$ with $10 \%$ nonfat dry milk.

212 Membranes were then probed for 1 hour at room temperature with Pan-Tau (Tau13, 1:10,000,

213 MMS-520R Covance), (GAPDH, 1:1000, ab9485 Abcam), Histone3 (1:1000, ab201456 Abcam),

214 RCC1 (1:100, Clone E-6 sc-55559 Santa Cruz Tech.), DNAJC2 (1:5000, ab134572 Abcam),

215 Histone 1.2 (1:500, ab4086 Abcam), HMGB1 (1:500, ab18256 Abcam), SMARCA5 (1:10000,

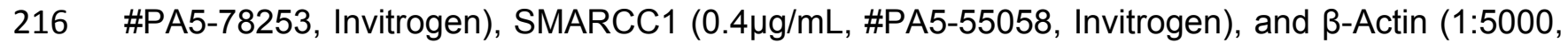

217 \#A1978, Sigma Aldrich). Antibodies were diluted in 5\% nonfat dry milk. Immunoreactivity was 218 detected using a horseradish peroxidase (HRP)-conjugated anti-rabbit immunoglobulin G (IgG, 219 1:10,000, NA934 GE Healthcare). Tau13 and Tau5 immunoreactivity were detected using an anti220 mouse IgG (1:10,000, NA931 GE Healthcare) diluted in 5\% milk. ECL Plus (K-12045-D50, GE

221 Healthcare) was used to visualize protein bands. LaminB1/Histone3 and GAPDH were used to 222 normalize and quantify nuclear and cytoplasmic proteins, respectively. The compartment 223 extraction was conducted with Qproteome Cell Compartment Kits (Qiagen, \#37502); nuclear, cell 224 membrane, and cytoplasmic proteins were isolated and preserved for IB analysis.

225 Immunofluorescence of Fixed Cells and Fluorescence Microscopy. Cells on a 24-well 226 coverslip were fixed with $0.5 \mathrm{ml}$ of $4 \%$ PFA/PBS for $15 \mathrm{~min}$. The cells were then washed 3 times 227 in phosphate buffered saline (PBS), for 5 min for each wash. The cells were permeabilized in $2280.5 \mathrm{ml}$ PBS and $0.2 \%$ Triton X-100 in phosphate buffered saline containing $0.5 \%$ Tween (PBST) 229 for $5 \mathrm{~min}$. Blocking was done in $0.5 \mathrm{ml}$ of $5 \%$ normal goat serum (NGS) in PBST for 1 hour. 230 Primary antibody was diluted in 5\% NGS/PBST overnight at $4^{\circ} \mathrm{C}$ for incubation, and then washed 2313 times in PBST, for 10 min each. Secondary antibody diluted in 5\% NGS/PBST was incubated 
232 for 2 hours at room temperature. All the secondary antibodies were purchased from Thermo

233 Fisher Scientific and used at a 1:800 dilution for staining. After applying secondary antibodies,

234 cells were incubated in DAPI (nuclei staining) diluted 1:10,000 in PBST (5 mg/ml stock solution)

235 for 5 min after the first wash. The cells were then washed 2 times with PBST, and once with PBS

236 (10 min each) prior to mounting coverslips. Coverslips were mounted on glass microscope slides

237 using 8-10 $\mu$ l of Prolong Gold Antifade mounting media with DAPI (Invitrogen, P36941) per

238 coverslip. Slides were air-dried in fume hood or stored at $4^{\circ} \mathrm{C}$ until ready to be dried in the fume

239 hood. The primary antibodies used in this study for immunocytochemistry (ICC) are as follows:

240 Histone 1.2 (Abcam ab4086 - $1 \mu \mathrm{g} / \mathrm{ml}$ ), Ki-67 (Abcam ab92742 - $1 \mu \mathrm{g} / \mathrm{ml}$ ), SMARCC1 (Invitrogen

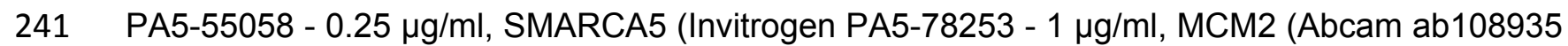

242 - 1/1000), RCC1 (Santa Cruz, INC. sc-55559 - 1:50), and Tau13 (Bio Legend MMS-520R - 1/200).

243 After three washes with PBS, cells were probed with mouse and rabbit-specific fluorescent-

244 labeled secondary antibodies (1:200, Alexa Fluor 488 and 633, Life Technologies). Single frame

245 images were collected using the Keyence BZ-X 710 Microscope. Images for quantification of area

246 and integrated density were taken in nuclear target areas guided by the DAPI fluorescence. We

247 then performed single extraction analysis using BZ-X Analyzer software (Keyence). We used 200

248 nuclei per target area and used the Nikon 20X objective for imaging and quantification analysis.

Statistical Analysis. All in-vitro experiments were performed in at least three biological

251 replicates. All data are presented as means \pm SD and were analyzed using GraphPad Prism

252 Software 6.0. Statistical analyses included the Student-t Test or one-way ANOVA followed by

253 Tukey’s Multiple Comparisons Test. Column means were compared using one-way ANOVA with

254 treatment as the independent variable. In addition, group means were compared using two-way

255 ANOVA considering factors for each treatment respectively. When ANOVA showed a significant

256 difference, pair-wise comparisons between group means were examined by the Tukey and

257 Dunnett Multiple Comparison Test. 


\section{Results}

WT tau up-regulates genes associated with cytoskeleton organization and nuclear

speckles/bodies. Firstly, we evaluated changes in gene expression profiles upon expression of

WT and P301L tau in iHEK cells that were induced with tetracycline (Tet). After 24h of Tet induction, we confirmed tau expression in the cytoplasm and nuclei of iHEK cells (Fig S1A). Total cellular RNA from WT and P301L tau (untreated (Control) and treated (+Tet)) study groups was extracted using TRIzol reagent and by following established protocol7,13. RNA was sequenced using Poly(A)-ClickSeq (PAC-Seq) to measure changes in gene expression and poly(A)-site usage $^{31}$. A schematic of the experimental design is provided in Fig 1A. Volcano scatterplots from WT and P301L tau iHEK (Fig 1B and 1C, respectively) demonstrate a substantial difference in the number of genes regulated by WT tau and P301L tau. After Tet induction in the WT tau iHEK cell system, we observed up-regulation of 88 genes and down-regulation of 30 genes (gene

271 names listed in Fig 1D). In the P301L tau iHEK cell system, these numbers dropped to 10 up272 regulated genes and only 1 down-regulated (gene names listed in Fig 1E).

Fig S1B displays the scatterplots of WT and P301L tau gene expression, while Fig S1C

274 reports the Principal Component Analysis (PCA). PCA demonstrates significant variation among 275 the study groups. More specifically, the analysis suggests a significant difference in transcriptional 276 activity of WT tau due to the higher number of genes modulated in comparison to the mutant

277 P301L tau form. Using EnrichR ${ }^{34}$, we established Gene Ontology (GO) of the biological processes, 278 molecular functions, and cellular components altered by both the up-regulated and the down279 regulated sets of genes. WT tau GO is summarized in Fig 2. WT tau up-regulated genes belonging 280 mainly to classes of cytoskeleton-dependent intracellular transport genes (GO: 0030705, 281 TUBA1A, TUBB2B TUBA1B, TUBB2A and HOOK3) and genes responsible for the regulation of 282 cytoskeleton organization (GO: 0051493). Imbalanced expression of tubulin and tau induces 
neuronal dysfunction in C. elegans, ${ }^{35}$ indicating that tau itself can disturb tubulin gene expression.

284 The reason behind this pronounced involvement of TUBB genes could be due to the fact that 285 TUBB1B, TUBB2B, TUBA1A and TUBB2A are clustered together within the genome ${ }^{36}$.

It is important to note that biological process such as microglial cell activation (GO: distribution (GO: 0048311, MAPT and MEF2A genes), morphogenesis (GO: 0070584, SUPV3L1

$292 \mathrm{p}=0.03892$ ), neurogenesis (GO 0022008, NOM1, MAPT and DAGLB genes), and positive regulation of cell death (GO 0010942, SAP3OBP, MAPT and CLU genes). The increase of CLU expression was a particularly interesting observation. Clusterin is a multifunctional, secreted chaperone involved in several basic biological events, including cell death, tumor progression and neurodegeneration. The CLU gene is notably associated with an increased AD risk ${ }^{39}$.In terms of molecular functions, the up-regulated genes we observed have several enriched pathways, including RNA binding (GO: 0003723, USP36, NOM1, TFRC, BAZ2A, SUPTSH, PHF6, FTSJ3, SUPV3L1, TUBA1B, RBM20, MAPT, RBM33, PELP1, HIST1H1C, CPEB4) and several nuclear

300 functions, such as histone deacetylase binding (GO: 0042826, MEF2A, SUDS3 and PHF6) and 301 sequence-specific double stranded DNA binding (GO: 1990837, MEF2A, KAT7 and MAPT).

303 nuclear compartments. We detected transcripts associated with nuclear chromatin (GO: 304 0000790), such as MEF2A, ZEB2, ANP32E, SUDS3, HIST2H2AC, and HIST1H1C. We also 305 examined nuclear speck transcripts (GO: 0016607), such as CARMIL1, USP36, GTF2H2C, $306 B A Z 2 A$, and MAPT genes, which are also included in nuclear body components (GO: 0016604), 307 along with SUDS3 and SENP2. The other cell compartment well represented in our GO analysis 
308 is the cytoplasm. In particular, the microtubule cytoskeleton (GO: 0015630) contained the

309 following up-regulated genes: TUBB2B, SAP30BP, TUBA1B, TUBA1A, TMOD3, MAP7, TARS,

310 TACC1, MAPT, CLU, and RHOQ. A complete Enrich-GO list of significant up-regulated genes

311 observed in WT tau is presented in Supplemental Table 1.

WT tau down-regulates genes involved in ubiquitin-related processes as well as

genes associated with Golgi and mitochondrial components. Overall, thirty genes were significantly downregulated by WT tau protein. The main biological process affected was the regulation of cellular component organization (GO: 0051128) as it relates to cytoskeleton

317 organization and structure morphogenesis. Molecular functions associated with the aforementioned genes are closely related to ubiquitin protein ligase binding (GO: 0031625) and ubiquitin-like protein ligase binding (GO: 0044389). Genes important to neuronal components

320 included genes essential to the structure of initial axonal segments, nodes of Ranvier, and main 321 axons. These three groups typically involve the gene KCNQ2. This gene encodes for Potassium 322 voltage-gated channel subfamily KQT member 2, which plays a critical role in determining the 323 subthreshold electrical excitability of neurons as well as the responsiveness of neurons to 324 synaptic inputs. Therefore, KCNQ2 is important in the regulation of neuronal excitability and the 325 loss-of-function or gain-of function of this gene can lead to various forms of neonatal epilepsy ${ }^{40}$.

326 Furthermore, Cullin-RING E3 ubiquitin-ligase complex component KLHL11 is down327 regulated, as well as the STX6 gene. STX6 encodes for Syntaxin-6, which is involved in 328 intracellular vesicle trafficking and is integrally associated with the Golgi apparatus. Another Golgi 329 protein that is down-regulated is Golgin-45 (BLZF1). It is required for normal Golgi structure and 330 for protein transport from the Endoplasmic Reticulum (ER) through the Golgi apparatus to the cell 331 surface ${ }^{41}$. Lastly, the ER gene STC2 is downregulated and encodes for Stanniocalcin-2. This 332 glycoprotein has an anti-hypocalcemic action on calcium and phosphate homeostasis ${ }^{42}$. 
We also detected two nucleolus-localized genes among the down-regulated group: UBE2T (ubiquitin-conjugating enzyme with E2 T) and UPF3A, (a regulator of nonsense transcript 3A). The mitochondrial genes that were down-regulated included OXCT1 (Succinyl-CoA: 3-

336 ketoacid coenzyme A transferase 1, mitochondrial enzyme), TRUB1 and PFDN2 (Prefoldin 337 subunit 2). An Enrich-GO list of downregulated genes present in WT tau is depicted in 338 Supplemental Table 2.

Although there are limitations inherent with the model used, these data suggest that WT tau intrinsically and significantly impacts the cell at a transcriptional level. More specifically, a

341 higher number of genes are up-regulated and down-regulated by WT tau when compared to 342 P301L tau. This suggests that the P301L mutation leads to a loss-of-function (LOF) of tau at the 343 transcriptional level. This sort of loss could have detrimental effects on cell structure and 344 organization.

P301L tau up-regulates gene expression of components related to axonal microtubule

347 skeleton, nuclear speckles, and ribonucleoprotein. The GO pathways and cellular 348 compartments upregulated and downregulated by P301L tau are listed In Supplemental Tables 3 349 and 4 respectively. As observed in WT tau iHEK cells, the MAPT gene is on the upregulated 350 gene list for P301L tau, as expected after Tet induction of the iHEK cells. Within the group of 351 axonal and cytoskeleton genes, we noticed up-regulation of NLGN1, a gene that encodes for 352 Neuroligin-1. Neuroligin is a postsynaptic neuronal surface protein involved in cell-to-cell 353 interactions via its interactions with neurexin family members ${ }^{43}$. It has been established that the 354 NLGN1 gene is associated with amyloid- $\beta$ oligomers (A $3 O s)$ in AD-causing synaptic impairment ${ }^{44}$. 355 In addition, NLGN1 is typically altered in AD hippocampi and also modulates amyloid-beta 356 oligomer toxicity ${ }^{45}$. Neuroligin-1 plays an influential role in synaptic function and synaptic signal 357 transmission, most likely through its ability to recruit and cluster together other synaptic proteins ${ }^{43}$. 
For instance, neuroligin-1 may promote the initial formation of synapses ${ }^{46}$, but is not essential for the complete formation of synapsyes. In vitro, Neuroligin-1 triggers the de novo formation of presynaptic structures. NLGN1 may also be involved in specification of excitatory synapses ${ }^{43}$. For example, NLGN1 functions to maintain wakefulness quality and normal synchrony of cerebral cortex activity during wakefulness and sleep ${ }^{47}$. Neuroligin-1 is predominantly located in synaptic cleff of the cell membrane ${ }^{48}$.

When we analyzed upregulated genes, we detected a considerable number of genes related to nuclear body (GO: 0016604) and nuclear speck (GO;0016607) domains including the genes ITPKC and MAPT. Interestingly, it has been observed that the FER gene participates in several different cytoplasmic and nuclear functions. For example, FER is associated with nuclear chromatin (GO:0000790) and the microtubule skeleton (GO:0015630). The FER gene also encodes for a tyrosine-protein kinase that plays a role in synapse organization, trafficking of synaptic vesicles, the generation of excitatory post-synaptic currents, and neuron-to-neuron 371 synaptic transmission ${ }^{49}$. Lastly, FER plays a role in neuronal cell death after brain damage ${ }^{49}$. The

372 only gene down-regulated by P301L tau is DCAF12, which is a component of the Cullin-RING 373 ubiquitin ligase complex ${ }^{50}$. This gene is also down-regulatated by WT tau and belongs to genes

374 associated with ubiquitinization processes. The failure of ubiquitinization pathways is known to 375 have a strong connection to neurodegenrative diseases ${ }^{51}$. Supplemental Figure 2 summerizes 376 upregulated and downregulated genes in P301L tau, subcatagorized by biological process and 377 molecular function.

In summary, the P301L mutation upregulates genes involved in positive regulation of

379 neuronal death and responsivness to reative oxygen species (ROS) production. This is in contrast 380 to the genes altered by WT tau that have a greater affect on cell structural processes. The most 381 important molecular function altered by such genes would be sequence-specific double-stranded 382 DNA binding, transcriptional expression, and chromatin remodelling. Overall, our GO data 
suggests the precense of both loss-of-function( LOF) and gain-of-function (GOF) events in mutated P301L tau that may relate to pathology. Modulating genes known to be associated with neurodegenerative disease suggests that muatted tau engenders harmful transcription patterns that contribute to the well-established effects of tau proteinaceus-aggregation toxicity.

\section{WT tau modulates gene expression of chromatin organization and remodeling factors.}

Gene Set Enrichment Analysis (GSEA) offers an opportunity to evaluate and identify classes of genes or proteins that are over-represented in a large set of genes or proteins and may have an association with disease phenotypes. Due to the differences in gene numbers modulated by WT tau versus P301L tau, we performed GSEA. This analysis compared models with and without WT tau. We observed that WT tau down-regulates the expression of numerous genes linked to chromatin organization (Fig 3A) and chromatin remodeling (Fig 3B) domains. By looking at the chromatin organization and remodeling gene clusters, we identified that several high-mobility group box proteins (HMG) HMGN5, HMGB2 and HMGA1 are up-regulated while HMGB1 and HMGN1 are down-regulated. It is important to note that HMGB1 is an activator of neuroinflammatory responses and has been implicated in $A D^{52}$. In addition, several components of the SWI/SFN chromatin remodeling complex are downregulated. The identification of genes SMARCE1, SMARCA5 and SMARCC1, imply that tau has a substantial impact on chromatin 401 remodeling in the cells. The heterogeneous nuclear ribonucleoproteins (hnRNPs), HNRNPU and 402 HNRNPC, were also found to be downregulated in WT tau. Down-regulation of several factors 403 implicated in DNA replication and repair processes, indicates that WT tau also significantly affects 404 the nuclear compartment of cells in terms of structure and content. Several of these genes are 405 clustered as covalent chromatin modification in GO (Fig 3C).

406 To validate gene expression changes observed in GSEA analysis, we verified multiple 407 proteins via western blot by using the up-regulated and down-regulated lists generated from 408 Histone Binding GO. We verified up-regulation of RCC1, DnaJC2 and Histone1.2 proteins in the 

RCC1 expression and noticed its accumulation in the cytoplasm for both cell lines. Interestingly,

411 we discerned that RCC1 is not imported into the nuclei where it should function as a regulator of

412 chromatin condensation. Instead, DnaJC2 in P301L tau iHEK cells appear to be downregulated.

413 However, Histone 1.2 is upregulated in both cell lines. We did not observe down-regulation of

414 the chromatin remodeling complex factors SMARCC1 and SMARCA5. Instead, we detected their

415 accumulation in the cytoplasmic fractions while in the presence of tau, which suggests a deficit in

416 these factors in the nuclei, as observed in our western blots. Lastly, HMGB1 and $\beta$-Actin are

417 down-regulated, but HMGB1 is not detected in the nuclei when in the presence of tau. Histone 3

418 was used as a nuclear loading control.

419 To verify gene expression results, alongside western blots, we performed co420 immunofluorescence in WT tau iHEK cells. We evaluated integrated density of Histone 1.2 (Fig 421 3E and 3F), Ki67 (Fig 3G and 3H), SMARCC1 (Fig 3I and 3J), and SMARCA5 (Fig 3K and 3L).

422 Analysis was performed by considering nuclear integrated density of "-" and "+" tau WT iHEK 423 proteins. To detect and confirm tau expression, we used the Tau13 antibody. MCM2 and RCC1 424 images and their relative integrated density quantifications are presented in Supplemental Fig. 4. GSEA analysis for WT tau revealed significant down-regulation in the pathways for 426 histone-binding (Fig 4A) and nucleosome organization clusters (Fig 4B). Several genes were 427 detected in the histone and nucleosome domains, which were recurring and can be viewed in the 428 chromatin gene list showed in Fig 3 . In addition, we observed an up-regulation of RCC1 (a 429 regulator of chromosome condensation), CTSL (Cathepsin L), MCM2 (Minichromosome 430 maintenance complex component 2), and DNAJC2 (DnaJ heat shock protein member C2). In 431 Nucleosome GO, we observed up-regulated HMGB2 and HMGA1 (high mobility group box B2 432 and A1). On the contrary, several Lysine acetylation regulators were downregulated: $B R D 3$ and 433 BRD9 (from BRD family), HDAC2, KDM5B, KAT7, and SFTD2. 
We also used western blotting to verify tau levels in cytoplasm and nuclear fractions of WT and P301L tau iHEK cells (Fig 4C and 4D, respectively). We found that upon Tet induction in

436 both compartments, tau was detected, which was previously observed ${ }^{7}$ and expected. Western

437 blot analysis demonstrated that tau is represented mainly in its monomeric form $\left(\mathrm{mTau}_{\mathrm{N}}\right)$ when

438 probing the nucleus. We compared the level of $\mathrm{mTau}_{\mathrm{N}}$ in both cell lines and we determined that

$439 \mathrm{mTau}_{\mathrm{N}}$ increased in both cell lines after Tet induction. However, the WT mTau was present in a 440 significantly higher level when compared to the P301L mTau $($ Fig 4E). This difference is due to

441 the higher MAPT transgene expression efficiency in WT tau iHEK cell lines as was confirmed by

442 RT-qPCR in a previous study7. These observations suggest that the monomeric form of tau

443 protein predominantly carries out transcriptional activity and that the P301L mutation did not affect

444 the nuclear import of tau, but instead modulated transcriptional activity. Cytoplasmic mTau was

445 quantified as well (Supplemental Figure 4). In general, we propose that WT and P301L tau both

446 shuttle into the nuclei but then modulate transcription differently. The schematic model for this

447 idea is represented in Fig 4F. In summary, many nuclear factor genes involved in several nuclear

448 activities, including chromatin condensation, are downregulated in WT tau, which indicates a 449 potential role of WT and P301L tau in the control of chromatin factors, expression and subsequent 450 cellular localization.

452 RNA metabolism, chromatin organization and HNRNPs precursor's display shortened

453 APAs in the presence of WT tau. From PAC-seq analysis, we identified 110 genes with 454 shortened 3'UTRs. The majority of these shortened genes belong to significant pathways 455 associated with mRNA processing (GO: 0006397), RNA Splicing (GO: 0000377, GO: 0000398), 456 and RNA metabolic processes (GO: 0016070) (Fig 5A). These domains share several genes: 457 HNRNPA3, SRRT, PRPF4B, CCAR1, LSM8; SNRNP40, HNRNPK, ZMAT2, ZC3H11A, 458 HNRNPF, PCBP2, SNRPE, and HNRNPC. The regulation of responses to DNA damage (GO: 
2001020) comprise the following genes: BCLAF1, FMR1, USP1 and HMGA2 (others listed in Fig $5 B)$.

Within the shortened APA precursors, various genes are related to nuclear function, such as the chromosome related genes (GO: 0005694) IK, FMR1, HMGA2, SMC4, SMC3, SMC2 and

463 SMC6. Structural maintenance of chromosome (SMC) proteins are ATPases that are essential to 464 chromosomal condensation, sister-chromatid cohesion, recombination, DNA repair, and 465 epigenetic silencing of gene expression ${ }^{53}$. Eukaryotes have at least six genes encoding SMCs $466($ SMC1-SMC6)54. They inherently work as heterodimers: SMC1/SMC3 (Cohesin Complex), SMC2/SMC4 (Condensin Complex) and SMC5/SMC654. including: PARP1, FMR1, CHD7, DDX21, PWP1, PPM1E, SMC2, RSL1D1, ILF3, NCL, S100A13,

470 KIF20B, RAN, and GET4. As we saw in the shortened 3'UTRs, the most affected genes for

471 lengthened 3' UTRs lie within the RNA binding function domain (GO: 0003723). MRNA

472 processing, RNA splicing, and nucleic acid metabolic processes received the top scores,

473 indicating a strong impact of WT tau in the regulation of mRNA isoforms at different levels. All

474 significant enrichment terms are clustered and represented in a scatterplot in Fig 5C. In the mRNA

475 processing domain (GO: 0006397) we identified several heterogeneous nuclear 476 ribonucleoproteins (hnRNPs) genes (HNRNPA3, HNRNPK, HNRNPF, HNRNPC, HNRNPDL).

477 HnRNPs are involved in alternative splicing, transcriptional and translational regulation, stress 478 granules formation, cell cycle regulation, and axonal transport ${ }^{55}$. Their dysfunction has been 479 shown have neurological implications, but their roles have not been comprehensively 480 investigated. Several neurodegenerative diseases, including AD, FTD, and amyotrophic lateral 481 sclerosis (ALS) have been associated with hnRNPs when it comes to the progression of these 482 pathologies ${ }^{56}$. More specifically, hnRNPK has been linked to the transcripts of several cytoskeletal 483 genes, including MAPT, which is needed for axonogenesis ${ }^{57}$. 
In Alzheimer's disease, hnRNPC promotes APP translation ${ }^{58}$ and stabilizes the APP precursors mRNA, which could suggest that increasing hnRNPC levels may promote $A \beta$ 486 secretion ${ }^{59}$. Within the hnRNPs group, hnRNPA3, hnRNPF and hnRNPDL are all detected in 487 pathological inclusions of ALS and FTD brains $56,60,61$. Moreover, hnRNPK is a regulator of $488 \mathrm{p} 53^{62}$, which we and others recently discovered was present in elevated amounts in $A D$ 489 cortices $^{11,12}$. It has been also determined that hnRNPK sumoylation mediates p53 activity ${ }^{63}$. All 490 this evidence places hnRNPs in a central position for further experimental analysis in human brain 491 tissues to elucidate more valuable information about the localization and function of this large 492 family of ribonucleoproteins.

HnRNPA3 has been identified in neuronal cytoplasmic and intranuclear inclusions in 494 patients with GGGGCC expansion repeats ${ }^{61}$ and hnRNP F were also found to co-localize with 495 GGGGCC expansion foci in immunoprecipitation studies ${ }^{64}$. In addition, western blot analyses 496 imply that hnRNP may be in part responsible for the toxicity incurring by C9orf72 mutations, 497 considering important RNA processes such as splicing are compromised. hnRNP A3 and $\mathrm{K}$ have been found associated with TDP-4365. Implications of tau-mediated APAs in hnRNPs open new 499 venues for investigators to study new mechanistic insights of these proteins in several 500 proteinophaties. Within RBPs group, we also observed the MATR3 gene. This gene encodes for 501 Matrin3, a DNA/RNA-binding protein. Mutations in this gene cause familial ALS/FTD, and MATR3 502 pathology is a feature of sporadic disease, suggesting that its dysfunction is inherently linked to 503 ALS pathogenesis ${ }^{66}$.

504 Shorter 3'UTR are generally associated with enhanced translation of the mRNA APA in 505 the presence of WT tau, which supports the finding that high-levels of hnRNPs sustain dysfunction 506 of stress granules in ALS and FTD. Recent proteomic analysis in AD human Neurofibrillary 507 Tangles (NFTs) showed that phospho-tau in NFTs is associated with more than 500 proteins $^{67}$. 508 We observed several of these proteins in the APAs shortened WT tau, such as HNRNPK, ILF3, 
AP2B1, RAN, RAB11A, HSP90B1, PARP1, MATR3, PPIA, NCL, HNRNPA3, HSP90AA1, and

HNRNPC. It is intriguing that the presence of chaperone Hsp90, a tau-regulated gene, plays a

511 crucial role in neurodegenerative pathologies and has been studied in AD or a long time ${ }^{68}$.

512 These observations suggest that tau has early effects on gene expression that results in

513 later stages of toxic associations commonly found in neurodegeneration. Enrich-GO (Cellular

514 Function) of shortened-APAs genes by WT tau is provided in the supplemental information

515 section. GO-Cellular Process, Molecular Process and Cellular Components bar charts of

516 shortened APAs are shown in Fig S4.

SWI/SFN, THO complexes, and several RNA-Binding protein precursors display

lengthened 3'UTRs in presence of WT tau. Further analysis revealed 173 genes with lengthened APAs. The complete list of the 173 genes with lengthened APAs is reported in the

521 supplemental information section. Among these genes, we found that many of them are related

522 to three major biological process: chromatin remodeling (GO:0006338), negative regulation of 523 gene expression (GO: 0010629), and mRNA processing (GO:0006397) (Fig 6A). To be more

524 specific, we noticed several genes belonging to the ATP-dependent chromatin remodeling 525 complex npBAF (mammalian SWI/SFN, GO: 0071564): SMARCC2, ARID1A, SMARCA2 and

526 SMARCA4. This complex is found in neuronal progenitor's cells and post-mitotic neurons, and it

527 is essential for the maturation of the post-mitotic neuronal phenotype as well as long-term memory

528 formation ${ }^{69}$. Along with the chromatin remodeling complex, other genes contained altered APAs,

529 including pericentric chromatin components (GO: 0005721, HELLS and CBX3), and nuclear

530 chromatin factors (GO:0000790, SMARCC2, CBX3, H3F3A, NUCKS1, ARID1A, SMARCA2,

531 SMARCA4, HIST2H2AC, RAD50, NASP, MYC, NSMF, TCF3) (Fig 6B).

532 Several nuclear speck (GO: 0016607) genes were also identified: BASP1, POM,; ERBI,

533 YLPM1, HNRNPU, LUC7L3, CDC5L, TCF3, SRSF6, and KIF20B. Cytoplasmic ribonucleoprotein 
534 granule (GO: 0036464) and cytoplasmic stress granules (GO: 0010494) genes were delineated

535 as MBNL1, CARHSP1, NCL, HNRNPU, IQGAP1, YBX1, RAC1, PABPC1, CNOT9. Within the

536 domain of RNA processing, two genes THOC2 and THOC3 were also identified. They are

537 components of the THO complex (GO: 0000445) involved in efficient export of poly-adenylated

538 RNA and spliced RNAs ${ }^{25}$

539 The THO complex appears to coordinate transcripts for synapses development and 540 dopamine neuron survival ${ }^{70}$. Recently, it has been found to interact with $\mathrm{ZC} 3 \mathrm{H} 14$, which regulates

541 the processing of neuronal transcripts ${ }^{71}$, so it is not surprising to find in our dataset another 542 polyadenosine RNA-binding protein $\mathrm{ZC} 3 \mathrm{H} 15$ on the list of lengthened APAs. These observations 543 indicate that export complex RNA precursors are meaningfully affected by WT tau.

$544 \quad$ Not surprisingly, many translation initiation factors (GO: 0003743) were also discovered 545 in our analysis including EIF2S3, EIF3E, EIF3A, EIF1, and EIF4G1. It is important to note that 546 many APA-lengthened proteins in our study are RNA-Binding Proteins (RBPs). In fact, 46/173, or $547 \sim 27 \%$ of the total were. RBPs are implicated in the pathogenesis and progression of numerous 548 neurodegenerative diseases, and they are linked to toxic interactions and aggregations in 549 amyloidogenic proteins such Amyloid-beta and tau. The subsequent dysfunction of RBPs is 550 closely related to distinct pathways that are altered in proteinophaties ${ }^{72}$.

551 Considering the above, we also studied the presence of lengthened APAs of ELAVL1.

552 This gene encodes for HuR (RBPs), which is a neuroprotective protein. This protein has been 553 demonstrated in the regulation of oxidative metabolism in neurons as a way to protect from 554 neurodegeneration ${ }^{73}$.

$555 \quad$ Apical dendrites (GO: 0097440) (MAP1B, NSMF and CLU) and other cytoskeletal genes 556 (ACTR2, LIMA1, TPM4, PPP2R1A, BASP1, TARS, PHIP, NSMF, IQGAP1, RAC1, CLU, and 557 SMARCA2) display lengthened poly-A tails as well. Enrich-GO (Cellular Function) of lengthened- 
APAs genes in WT tau is provided in the supplemental information section. GO-Cellular Process, Molecular Process and Cellular Components bar charts of lengthened-APAs are shown in Fig S4.

\section{P301L tau modulates 3'UTRs of RNA export complex THOC and splicing precursors}

562 SNRPE. In P301L tau precursor APAs, we detected 23 lengthened genes in total. More 563 specifically, the THOC2 gene, which is a component of the THO complex (GO: 0000445) was 564 lengthened in WT tau. Another gene of the small nuclear ribonucleoprotein complex (SNRPE) 565 was detected. SNRPE is also a gene for the spliceosome complex (GO: 0005681) (Fig 7A). Lastly, 566 the nuclear replication fork (GO: 0043596) gene BAZ1B was also observed. represent a large RNA-Binding protein family that contributes to many aspects of nucleic acid metabolism, including alternative splicing, mRNA stabilization, transcriptional, and translational

570 regulation ${ }^{55}$. Dysregulation of RNA metabolism is crucial in the pathogenesis of several

571 neurodegenerative diseases as Parkinson's ${ }^{74}$, FTD and overlaps with aspects of ALS. Some 572 studies revealed possible involvement of hnRNPs in the pathogenesis and progression of these 573 diseases ${ }^{75}$. Furthermore, hnRNP F has been uncovered in RNA foci in human brain tissue of FTD574 ALS patients ${ }^{56}$. Affinity pull-down assays and genome-wide analysis also revealed a hnRNP F575 bound splicing complex that regulates neuronal and oligodendroglial differentiation pathways in 576 the developing brain ${ }^{64}$. As observed for WT tau, the mutant P301L form also modulates several 577 RNA-Binding Proteins (GO: 0003723): SLFN11, HNRNPF, FASN, HUWE1, PRRC2C, THOC2, 578 HMGN2, SRSF7, and GIGYF7. We found 34 genes in total with evidence of APA and shortened 579 3'UTRs (Fig 7B). The three top-scored cellular components were nuclear speck (GO: 0016607), 580 nuclear body (GO: 0016604) with RBM39 (ALS associated gene ${ }^{76}$ ) and Nuclear heterochromatin 581 genes (GO: 0005720). Nuclear speak and body genes consisted of LUC7L3, SRSF4, NSRP1 and 582 SRSF11. Nuclear heterochromatin genes detected were H2AFY and HIST1H1E. H2AFY encodes 
583 for a variant of the $\mathrm{H} 2 \mathrm{~A}$ histone that is present in a subset of nucleosomes where its role is to

584 represses transcription ${ }^{77}$.

585 The Cellular Components scatterplot of lengthened APAs in WT Tau is presented in Fig

$5866 \mathrm{C}$ and GO Cellular component bar charts in Fig 6D.

587 These data suggest that the mutant P301L form of tau reduces activity in transcription and

588 alternative poly(A) tails processes due to loss-of-function. However, P301L tau does generate

589 different mRNA isoforms of transcripts mainly translated in splicing factors, nuclear speckle/body

590 structures and chromatin remodeling proteins. Enrich-GO (Cellular Function) of shortened and

591 lengthened-APAs by P301L tau is provided in the supplemental information section. GO-Cellular

592 Process, Molecular Process and Cellular Components bar charts of shortened and lengthened-

593 APAs are shown in Fig S4. 


\section{Discussion}

609 In this study, we revealed new mechanistic insights into non-canonical tau functions. In particular,

610 we showed novel tau activities in transcription and alternative poly-adenylation (APA) pathways.

611 APA is a widespread mechanism of gene regulation that generates 3' ends in transcripts made

612 by RNA polymerase $\mathrm{II}^{78}$. APA is regulated in cell proliferation, differentiation and extracellular

613 cues. It occurs in the 3'UTR and leads to the production of mRNA isoforms, followed by splicing

614 which leads to the production of distinct protein isoforms ${ }^{78}$. Tau is typically described as an

615 abundant neuronal microtubule-binding protein. Recently, we observed its presence within non-

616 neuronal human cell lines and neuronal nuclei in AD brains ${ }^{7,13}$ alongside other study ${ }^{2}$. We were

617 particularly interested in the possibility of non-canonical tau functions. We hypothesized that

618 nuclear tau acts as a transcriptional regulator. To test our hypothesis, we used the tau inducible

619 HEK system, which is a well-established cell line capable of studying mechanisms related to the

620 tau aggregation process within a controlled system of MAPT gene expression ${ }^{79}$. Our study

621 employed new technologies such as Poly(A)-ClickSeq to resolve whether genes were

622 upregulated or downregulated by WT and P301L tau in an in-vitro model. Furthermore, we 623 analyzed alternative polyadenylation (APA) profiles under the presence of WT and P301L tau ${ }^{76}$.

624 Our results suggest that both WT and P301L tau are able to shuttle into the nuclei (Fig 4).

625 This observation confirmed our previous observations ${ }^{7}$. We did not investigate the effect of the

626 P301L mutation on nuclei-cytoplasm shuttling in this report. The decreased number of genes

627 expressed in P301L cells suggests that this particular mutation of tau impairs transcriptional

628 activity. We did not investigate the LOF consequences of P301L tau in great detail, but our

629 observations suggest new mechanistic insights linked to alternative nuclear tau function.

630 One APA transcript of significance is the SFPQ gene, which we identified in WT tau

631 expression as having a lengthened 3'UTR. SFPQ has been associated with tau as a critical factor

632 for rapid progression of $A D$, and it has been observed as downregulated in post-mortem brain 
633 tissue of rapidly progressive AD patients ${ }^{80}$. Therefore, the lengthened APAs in this gene could

634 explain the down-regulation in the presence of a high level of tau, which mimics late-stage AD.

635 In-vitro data of SFPQ down-regulation due to human tau suggest a causal role of tau, possibly 636 through the alternative poly-adenylation of SFPQ transcripts.

637 Further analysis comparing 3'UTRs lengthened between WT and P301L tau revealed that 638 a significant number of RBPs showed lengthened 3'UTRs in P301L compared to WT tau. For 639 example, we detected 72 RBPs including FUS (found in the supplemental information section). 640 These data suggest a significant difference in RNA isoforms based on genetic tau background, 641 which then subsequently modulates different aspects of RNA metabolism in neurons.

642 Using the same cellular models, we determined that the prominent form of nuclear tau is 643 monomeric, but Tet induction causes tau oligomerization within the nuclei ${ }^{7}$. The formation of large 644 and nuclear oligomeric forms is another possible explanation for LOF observed as a consequence 645 of mutated tau. Mutant P301L tau shows a distinct aggregation mechanism compared to $\mathrm{WT}^{81}$ 646 and aggregates faster than $\mathrm{WT}^{82,83}$. For example, monomeric tau in the cytoplasm of cells 647 producing (WT or $\mathrm{P} 301 \mathrm{~L})$ tau aggregate and subsequently avoid nuclear translocation. In 648 addition, aggregation in the cytoplasm and within the nuclei of tau reduces the pool of monomeric 649 nuclear tau. This pathological mechanism can compete with functional monomeric and oligomeric 650 tau, which then alters tau transcriptional activity. This phenomenon should be investigated in the 651 near future using neuronal models. Another function of tau is binding DNA in-vitro. Overall, the 652 multifunctional nature of nuclear tau should be thoroughly scrutinized in order to identify 653 unrevealed functions connected to DNA expression and RNA processing. We suggest that the 654 nature of nuclear tau as a transcriptional factor, chromatin remodeler and/or transcriptional co655 factor must be elucidated using proper models such as induced pluripotent stem cells or mouse 656 primary neurons carrying mutation on P301 site. At this stage, we can only hypothesize the direct 657 and indirect effects of tau during transcription. 
This study utilized PAC-ClickSeq technology to identify the APA modulated by P301L and WT tau. Alternative Poly-A (APA) sites in human genome have been identify mainly in 3'UTRs

660 (UTR-APA) sites, which harbor diverse regulatory sequences. This type of APA can change the

661 length and composition of 3'UTR, which subsequently affects the binding of miRNAs and/or

662 RBPs. This post-transcriptional modification leads to differences in mRNA stability, export, 663 localization, translational efficiency ${ }^{26}$. Although the currently accepted theory is that genes with

664 longer 3'UTR tend to show decreased expression levels, this does not necessarily mean that 665 every single gene with a longer 3'UTR is less stable those with a shorter one.

We plan to investigate these findings using primary neurons and in-vivo models in the

667 near future. We are choosing these alternative models because the iHEK cell model have inherent

668 limitations in terms of reliability as a neuronal system. However, the iHEK cells used in this study

669 are an established model used by many researchers to study the mechanistic insights of tau

670 aggregation and toxicity. The results presented in this study support non-canonical functions of

671 tau. Therefore, we report broad tau-driven, post-transcriptional regulation in APAs by both WT

672 and P301L tau considering both cell lines produced high levels of monomeric and aggregated

673 tau. In this study, we did not investigate which tau isoform regulates APA in cells and by what

674 method tau regulates APAs, but we established a new category of interest in post-translational

675 modification. We hope further studies of nuclear tau and its relation to DNA and RNA processing

676 will identify new targets in tauopathies and eventually find new therapeutic targets. 
Limitations of the study. As mentioned in the discussion, the main limitation of this study is the nature of tau inducible HEK cells. We are aware that further study on neuronal cells is necessary. However, iHEK models are commonly used to study mechanisms that are tau-dependent and several of them have been translated into neurons models. All relevant datasets used and/or analyzed in this current study are available upon request from the corresponding author.

Supplemental Information. The source data underlying all main and supplementary figures are provided as a Source Data file. RNAseq datasets is uploaded to NCBI SRA, reference number: PRJNA744518. Figure 1A, 4F and 7C were generated using BioRender Software (https://biorender.com).

Acknowledgments and Funding. We thank the members of the Kayed and Routh labs for their support and help. We thank Bergman Isabelle B. and Leiana Fung for editing and proofreading of the manuscript. This work was supported by Mitchell Center for Neurodegenerative Diseases,

694 the Gillson Longenbaugh Foundation and National Institute of Health grants: R01AG054025, R01NS094557, R01AG055771, R01AG060718 and the American Heart Association collaborative grant 17CSA33620007 (R.K.).

Author contribution. Conceptualization, M.M., A.R. and R.K.; Methodology, M.M., A.R. and Writing - Original Draft, M.M.; Writing - Review \& Editing, all authors; Funding Acquisition, R.K.;

701 Resources, R.K.; Supervision, M.M. and R.K.

\section{Declaration of Interests}

704 The authors declare no competing interests. 
706

707

708

709

710

711

712

713

714

715

716

717

718

719

720

721

722

723

724

725

726

727

728

729

730

731

732

733

734

735

736

737

738

739

740

741

742

743

744

745

746

747

748

\section{References}

1. Sultan A, Nesslany F, Violet M, et al. Nuclear tau, a key player in neuronal DNA protection. The Journal of biological chemistry. 2011;286(6):4566-4575. doi:10.1074/jbc.M110.199976

2. Violet $M$, Delattre $L$, Tardivel $M$, et al. A major role for Tau in neuronal DNA and RNA protection in vivo under physiological and hyperthermic conditions. Frontiers in cellular neuroscience. 2014;8:84. doi:10.3389/fncel.2014.00084

3. Hua Q, He R. Tau could protect DNA double helix structure. Biochimica et biophysica acta. 2003;1645(2):205-211. doi:10.1016/s1570-9639(02)00538-1

4. Zhang $X$, Lin $\mathrm{Y}$, Eschmann NA, et al. RNA stores tau reversibly in complex coacervates. PLoS biology. 2017;15(7):e2002183. doi:10.1371/journal.pbio.2002183

5. Kampers T, Friedhoff $P$, Biernat J, Mandelkow EM, Mandelkow E. RNA stimulates aggregation of microtubule-associated protein tau into Alzheimer-like paired helical filaments. FEBS letters. 1996;399(3):344-349. doi:10.1016/s0014-5793(96)01386-5

6. Monroy-Ramírez HC, Basurto-Islas G, Mena R, et al. Alterations in the nuclear architecture produced by the overexpression of tau protein in neuroblastoma cells. Journal of Alzheimer's disease : JAD. 2013;36(3):503-520. doi:10.3233/JAD-122401

7. Montalbano M, McAllen S, Sengupta U, et al. Tau oligomers mediate aggregation of RNAbinding proteins Musashi1 and Musashi2 inducing Lamin alteration. Aging cell. Published online September 2019:e13035. doi:10.1111/acel.13035

8. Loomis PA, Howard TH, Castleberry RP, Binder LI. Identification of nuclear tau isoforms in human neuroblastoma cells. Proceedings of the National Academy of Sciences of the United States of America. 1990;87(21):8422-8426. doi:10.1073/pnas.87.21.8422

9. Shea TB, Cressman CM. A 26-30 kDa developmentally-regulated tau isoform localized within nuclei of mitotic human neuroblastoma cells. International journal of developmental neuroscience : the official journal of the International Society for Developmental Neuroscience. 1998;16(1):41-48. doi:10.1016/s0736-5748(97)00044-0

10. Ulrich G, Salvade A, Boersema $P$, et al. Phosphorylation of nuclear Tau is modulated by distinct cellular pathways. Scientific reports. 2018;8(1):17702. doi:10.1038/s41598-01836374-4

11. Baquero J, Varriano S, Ordonez M, et al. Nuclear Tau, p53 and Pin1 Regulate PARNMediated Deadenylation and Gene Expression. Frontiers in Molecular Neuroscience. 2019;12:242. doi:10.3389/fnmol.2019.00242

12. Farmer KM, Ghag G, Puangmalai N, Montalbano M, Bhatt N, Kayed R. P53 aggregation, interactions with tau, and impaired DNA damage response in Alzheimer's disease. Acta Neuropathologica Communications. 2020;8(1):132. doi:10.1186/s40478-020-01012-6

13. Montalbano M, McAllen S, Puangmalai N, et al. RNA-binding proteins Musashi and tau soluble aggregates initiate nuclear dysfunction. Nature Communications. 2020;11(1):4305. doi:10.1038/s41467-020-18022-6

14. Venkatramani A, Panda D. Regulation of neuronal microtubule dynamics by tau: Implications for tauopathies. International journal of biological macromolecules. 2019;133:473-483. doi:10.1016/j.ijbiomac.2019.04.120 
15. Maina MB, Bailey $\amalg$, Wagih $S$, et al. The involvement of tau in nucleolar transcription and the stress response. Acta neuropathologica communications. 2018;6(1):70. doi:10.1186/s40478-018-0565-6

16. Maina MB, Bailey $\amalg$, Doherty AJ, Serpell LC. The Involvement of Abeta42 and Tau in Nucleolar and Protein Synthesis Machinery Dysfunction. Frontiers in cellular neuroscience. 2018;12:220. doi:10.3389/fncel.2018.00220

17. Lester E, Parker R. The Tau of Nuclear-Cytoplasmic Transport. Neuron. 2018;99(5):869871. doi:10.1016/j.neuron.2018.08.026

18. Paonessa F, Evans LD, Solanki R, et al. Microtubules Deform the Nuclear Membrane and Disrupt Nucleocytoplasmic Transport in Tau-Mediated Frontotemporal Dementia. Cell reports. 2019;26(3):582-593.e5. doi:10.1016/j.celrep.2018.12.085

19. Tripathi T, Prakash J, Shav-Tal Y. Phospho-Tau Impairs Nuclear-Cytoplasmic Transport. ACS chemical neuroscience. 2019;10(1):36-38. doi:10.1021/acschemneuro.8b00632

20. Eftekharzadeh B, Daigle JG, Kapinos LE, et al. Tau Protein Disrupts Nucleocytoplasmic Transport in Alzheimer's Disease. Neuron. 2018;99(5):925-940.e7. doi:10.1016/j.neuron.2018.07.039

21. Siano G, Varisco M, Caiazza MC, et al. Tau Modulates VGluT1 Expression. Journal of molecular biology. 2019;431(4):873-884. doi:10.1016/j.jmb.2019.01.023

22. Klein $\mathrm{H}-\mathrm{U}, \mathrm{McC}$ abe $\mathrm{C}$, Gjoneska $\mathrm{E}$, et al. Epigenome-wide study uncovers large-scale changes in histone acetylation driven by tau pathology in aging and Alzheimer's human brains. Nature neuroscience. 2019;22(1):37-46. doi:10.1038/s41593-018-0291-1

23. Mansuroglu Z, Benhelli-Mokrani H, Marcato V, et al. Loss of Tau protein affects the structure, transcription and repair of neuronal pericentromeric heterochromatin. Scientific reports. 2016;6:33047. doi:10.1038/srep33047

24. Benhelli-Mokrani H, Mansuroglu Z, Chauderlier A, et al. Genome-wide identification of genic and intergenic neuronal DNA regions bound by Tau protein under physiological and stress conditions. Nucleic acids research. 2018;46(21):11405-11422. doi:10.1093/nar/gky929

25. Stewart M. Polyadenylation and nuclear export of mRNAs. The Journal of biological chemistry. 2019;294(9):2977-2987. doi:10.1074/jbc.REV118.005594

26. Gruber AJ, Zavolan M. Alternative cleavage and polyadenylation in health and disease. Nature Reviews Genetics. 2019;20(10):599-614. doi:10.1038/s41576-019-0145-z

27. Tian B, Hu J, Zhang H, Lutz CS. A large-scale analysis of mRNA polyadenylation of human and mouse genes. Nucleic Acids Research. 2005;33(1):201-212. doi:10.1093/nar/gki158

28. Shepard PJ, Choi E-A, Lu J, Flanagan LA, Hertel KJ, Shi Y. Complex and dynamic landscape of RNA polyadenylation revealed by PAS-Seq. RNA (New York, NY). 2011;17(4):761-772. doi:10.1261/rna.2581711

29. Rio DC, Ares MJ, Hannon GJ, Nilsen TW. Purification of RNA using TRIzol (TRI reagent). Cold Spring Harbor protocols. 2010;2010(6):pdb.prot5439. doi:10.1101/pdb.prot5439

30. Jaworski E, Routh A. ClickSeq: Replacing Fragmentation and Enzymatic Ligation with Click-Chemistry to Prevent Sequence Chimeras. Methods in molecular biology (Clifton, NJ). 2018;1712:71-85. doi:10.1007/978-1-4939-7514-3_6

31. Elrod ND, Jaworski EA, Ji P, Wagner EJ, Routh A. Development of Poly(A)-ClickSeq as a tool enabling simultaneous genome-wide poly(A)-site identification and differential 
expression analysis. Methods (San Diego, Calif). 2019;155:20-29.

doi:10.1016/j.ymeth.2019.01.002

32. Routh A. DPAC: A Tool for Differential Poly(A)-Cluster Usage from Poly(A)-Targeted RNAseq Data. G3 (Bethesda, Md). 2019;9(6):1825-1830. doi:10.1534/g3.119.400273

33. Kim D, Paggi JM, Park C, Bennett C, Salzberg SL. Graph-based genome alignment and genotyping with HISAT2 and HISAT-genotype. Nature Biotechnology. 2019;37(8):907-915. doi:10.1038/s41587-019-0201-4

34. Kuleshov M v, Jones MR, Rouillard AD, et al. Enrichr: a comprehensive gene set enrichment analysis web server 2016 update. Nucleic Acids Research. 2016;44(W1):W90W97. doi:10.1093/nar/gkw377

35. Miyasaka T, Shinzaki Y, Yoshimura S, et al. Imbalanced Expression of Tau and Tubulin Induces Neuronal Dysfunction in C. elegans Models of Tauopathy. Frontiers in Neuroscience. 2018;12:415. doi:10.3389/fnins.2018.00415

36. Bittermann E, Abdelhamed Z, Liegel RP, et al. Differential requirements of tubulin genes in mammalian forebrain development. PLOS Genetics. 2019;15(8):e1008243. https://doi.org/10.1371/journal.pgen.1008243

37. Kwon HS, Koh S-H. Neuroinflammation in neurodegenerative disorders: the roles of microglia and astrocytes. Translational Neurodegeneration. 2020;9(1):42. doi:10.1186/s40035-020-00221-2

38. Morales I, Jiménez JM, Mancilla M, Maccioni RB. Tau oligomers and fibrils induce activation of microglial cells. Journal of Alzheimer's disease : JAD. 2013;37(4):849-856. doi:10.3233/JAD-131843

39. Karch CM, Goate AM. Alzheimer's disease risk genes and mechanisms of disease pathogenesis. Biological psychiatry. 2015;77(1):43-51.

doi:10.1016/j.biopsych.2014.05.006

40. Niday Z, Hawkins VE, Soh H, Mulkey DK, Tzingounis A v. Epilepsy-Associated KCNQ2 Channels Regulate Multiple Intrinsic Properties of Layer 2/3 Pyramidal Neurons. The Journal of neuroscience : the official journal of the Society for Neuroscience. 2017;37(3):576-586. doi:10.1523/JNEUROSCI.1425-16.2016

41. Short B, Preisinger C, Körner R, Kopajtich R, Byron O, Barr FA. A GRASP55-rab2 effector complex linking Golgi structure to membrane traffic . Journal of Cell Biology. 2001;155(6):877-884. doi:10.1083/jcb.200108079

42. Ito D, Walker JR, Thompson CS, et al. Characterization of stanniocalcin 2, a novel target of the mammalian unfolded protein response with cytoprotective properties. Molecular and cellular biology. 2004;24(21):9456-9469. doi:10.1128/MCB.24.21.9456-9469.2004

43. Bemben MA, Shipman SL, Nicoll RA, Roche KW. The cellular and molecular landscape of neuroligins. Trends in neurosciences. 2015;38(8):496-505. doi:10.1016/j.tins.2015.06.004

44. Brito-Moreira J, Lourenco $M$ v, Oliveira MM, et al. Interaction of amyloid- $\beta$ (A $\beta$ ) oligomers with neurexin $2 \alpha$ and neuroligin 1 mediates synapse damage and memory loss in mice. The Journal of biological chemistry. 2017;292(18):7327-7337. doi:10.1074/jbc.M116.761189

45. Dufort-Gervais J, Provost C, Charbonneau L, et al. Neuroligin-1 is altered in the hippocampus of Alzheimer's disease patients and mouse models, and modulates the 
toxicity of amyloid-beta oligomers. Scientific reports. 2020;10(1):6956. doi:10.1038/s41598-020-63255-6

46. Craig AM, Kang Y. Neurexin-neuroligin signaling in synapse development. Current opinion in neurobiology. 2007;17(1):43-52. doi:10.1016/j.conb.2007.01.011

47. Helou J el, Bélanger-Nelson E, Freyburger $M$, et al. Neuroligin-1 links neuronal activity to sleep-wake regulation. Proceedings of the National Academy of Sciences of the United States of America. 2013;110(24):9974-9979. http://www.jstor.org/stable/42706115

48. Wu X, Morishita WK, Riley AM, Hale WD, Südhof TC, Malenka RC. Neuroligin-1 Signaling Controls LTP and NMDA Receptors by Distinct Molecular Pathways. Neuron. 2019;102(3):621-635.e3. doi:10.1016/j.neuron.2019.02.013

49. Lee S-H, Peng I-F, Ng YG, et al. Synapses are regulated by the cytoplasmic tyrosine kinase Fer in a pathway mediated by 120 catenin, Fer, SHP-2, and beta-catenin. The Journal of cell biology. 2008;183(5):893-908. doi:10.1083/jcb.200807188

50. Patrón LA, Nagatomo K, Eves DT, et al. Cul4 ubiquitin ligase cofactor DCAF12 promotes neurotransmitter release and homeostatic plasticity. The Journal of cell biology. 2019;218(3):993-1010. doi:10.1083/jcb.201805099

51. Zheng C, Geetha T, Babu JR. Failure of ubiquitin proteasome system: risk for neurodegenerative diseases. Neuro-degenerative diseases. 2014;14(4):161-175. doi:10.1159/000367694

52. Paudel YN, Angelopoulou E, Piperi C, Othman I, Aamir K, Shaikh MF. Impact of HMGB1, RAGE, and TLR4 in Alzheimer's Disease (AD): From Risk Factors to Therapeutic Targeting. Cells. 2020;9(2). doi:10.3390/cells9020383

53. Yatskevich S, Rhodes J, Nasmyth K. Organization of Chromosomal DNA by SMC Complexes. Annual review of genetics. 2019;53:445-482. doi:10.1146/annurev-genet112618-043633

54. Aragon L, Martinez-Perez E, Merkenschlager M. Condensin, cohesin and the control of chromatin states. Current opinion in genetics \& development. 2013;23(2):204-211. doi:10.1016/j.gde.2012.11.004

55. Geuens T, Bouhy D, Timmerman V. The hnRNP family: insights into their role in health and disease. Human genetics. 2016;135(8):851-867. doi:10.1007/s00439-016-1683-5

56. Lee $\mathrm{Y}-\mathrm{B}, \mathrm{Chen} \mathrm{H}-\mathrm{J}$, Peres JN, et al. Hexanucleotide Repeats in ALS/FTD Form LengthDependent RNA Foci, Sequester RNA Binding Proteins, and Are Neurotoxic. Cell Reports. 2013;5(5):1178-1186. doi:https://doi.org/10.1016/j.celrep.2013.10.049

57. Liu Y, Szaro BG. hnRNP K post-transcriptionally co-regulates multiple cytoskeletal genes needed for axonogenesis. Development. 2011;138(14):3079 LP - 3090. doi:10.1242/dev.066993

58. Lee EK, Kim HH, Kuwano Y, et al. hnRNP C promotes APP translation by competing with FMRP for APP mRNA recruitment to P bodies. Nature structural \& molecular biology. 2010;17(6):732-739. doi:10.1038/nsmb.1815

59. Rajagopalan LE, Westmark CJ, Jarzembowski JA, Malter JS. hnRNP C increases amyloid precursor protein (APP) production by stabilizing APP mRNA. Nucleic acids research. 1998;26(14):3418-3423. doi:10.1093/nar/26.14.3418

60. Gami-Patel P, Bandopadhyay R, Brelstaff J, Revesz T, Lashley T. The presence of heterogeneous nuclear ribonucleoproteins in frontotemporal lobar degeneration with 
FUS-positive inclusions. Neurobiology of aging. 2016;46:192-203. doi:10.1016/j.neurobiolaging.2016.07.004

61. Mori K, Lammich S, Mackenzie IRA, et al. hnRNP A3 binds to GGGGCC repeats and is a constituent of p62-positive/TDP43-negative inclusions in the hippocampus of patients with C9orf72 mutations. Acta neuropathologica. 2013;125(3):413-423. doi:10.1007/s00401-013-1088-7

62. Low Y-H, Asi Y, Foti SC, Lashley T. Heterogeneous Nuclear Ribonucleoproteins: Implications in Neurological Diseases. Molecular Neurobiology. 2021;58(2):631-646. doi:10.1007/s12035-020-02137-4

63. Pelisch F, Pozzi B, Risso G, Muñoz MJ, Srebrow A. DNA damage-induced heterogeneous nuclear ribonucleoprotein $\mathrm{K}$ sumoylation regulates p53 transcriptional activation. The Journal of biological chemistry. 2012;287(36):30789-30799. doi:10.1074/jbc.M112.390120

64. Mandler MD, Ku L, Feng Y. A cytoplasmic quaking I isoform regulates the hnRNP F/Hdependent alternative splicing pathway in myelinating glia. Nucleic Acids Research. 2014;42(11):7319-7329. doi:10.1093/nar/gku353

65. Moujalled D, Grubman A, Acevedo K, et al. TDP-43 mutations causing amyotrophic lateral sclerosis are associated with altered expression of RNA-binding protein hnRNP K and affect the Nrf2 antioxidant pathway. Human Molecular Genetics. 2017;26(9):1732-1746. doi:10.1093/hmg/ddx093

66. Malik AM, Miguez RA, Li X, Ho Y-S, Feldman EL, Barmada SJ. Matrin 3-dependent neurotoxicity is modified by nucleic acid binding and nucleocytoplasmic localization. Taylor JP, ed. eLife. 2018;7:e35977. doi:10.7554/eLife.35977

67. Drummond E, Pires G, MacMurray C, et al. Phosphorylated tau interactome in the human Alzheimer's disease brain. Brain : a journal of neurology. 2020;143(9):2803-2817. doi:10.1093/brain/awaa223

68. Campanella C, Pace A, Caruso Bavisotto C, et al. Heat Shock Proteins in Alzheimer's Disease: Role and Targeting. International Journal of Molecular Sciences . 2018;19(9). doi:10.3390/ijms19092603

69. Sokpor G, Xie Y, Rosenbusch J, Tuoc T. Chromatin Remodeling BAF (SWI/SNF) Complexes in Neural Development and Disorders. Frontiers in molecular neuroscience. 2017;10:243. doi:10.3389/fnmol.2017.00243

70. Maeder $\mathrm{Cl}$, Kim J-I, Liang X, et al. The THO Complex Coordinates Transcripts for Synapse Development and Dopamine Neuron Survival. Cell. 2018;174(6):1436-1449.e20. doi:10.1016/j.cell.2018.07.046

71. Morris KJ, Corbett $\mathrm{AH}$. The polyadenosine RNA-binding protein $\mathrm{ZC} 3 \mathrm{H} 14$ interacts with the THO complex and coordinately regulates the processing of neuronal transcripts. Nucleic acids research. 2018;46(13):6561-6575. doi:10.1093/nar/gky446

72. Maziuk B, Ballance HI, Wolozin B. Dysregulation of RNA Binding Protein Aggregation in Neurodegenerative Disorders. Frontiers in molecular neuroscience. 2017;10:89. doi:10.3389/fnmol.2017.00089

73. Skliris A, Papadaki O, Kafasla P, et al. Neuroprotection requires the functions of the RNAbinding protein HuR. Cell death and differentiation. 2015;22(5):703-718.

doi:10.1038/cdd.2014.158 
924 74. Lu B, Gehrke S, Wu Z. RNA metabolism in the pathogenesis of Parkinson's disease. Brain research. 2014;1584:105-115. doi:10.1016/j.brainres.2014.03.003

926 75. Bampton A, Gittings LM, Fratta P, Lashley T, Gatt A. The role of hnRNPs in frontotemporal dementia and amyotrophic lateral sclerosis. Acta Neuropathologica. 2020;140(5):599623. doi:10.1007/s00401-020-02203-0

76. Couthouis J, Hart MP, Shorter J, et al. A yeast functional screen predicts new candidate ALS disease genes. Proceedings of the National Academy of Sciences of the United States of America. 2011;108(52):20881-20890. doi:10.1073/pnas.1109434108

77. Doyen $\mathrm{C}-\mathrm{M}, \mathrm{An} \mathrm{W}$, Angelov $\mathrm{D}$, et al. Mechanism of polymerase II transcription repression by the histone variant macroH2A. Molecular and cellular biology. 2006;26(3):1156-1164. doi:10.1128/MCB.26.3.1156-1164.2006

78. Tian B, Manley JL. Alternative cleavage and polyadenylation: the long and short of it. Trends in biochemical sciences. 2013;38(6):312-320. doi:10.1016/j.tibs.2013.03.005

79. Koren SA, Hamm MJ, Meier SE, et al. Tau drives translational selectivity by interacting with ribosomal proteins. Acta Neuropathologica. 2019;137(4):571-583. doi:10.1007/s00401-019-01970-9

80. Younas N, Zafar S, Shafiq M, et al. SFPQ and Tau: critical factors contributing to rapid progression of Alzheimer's disease. Acta neuropathologica. 2020;140(3):317-339. doi:10.1007/s00401-020-02178-y

81. Strang KH, Croft CL, Sorrentino ZA, Chakrabarty P, Golde TE, Giasson BI. Distinct differences in prion-like seeding and aggregation between Tau protein variants provide mechanistic insights into tauopathies. The Journal of biological chemistry. 2018;293(7):2408-2421. doi:10.1074/jbc.M117.815357

82. Aoyagi $\mathrm{H}$, Hasegawa M, Tamaoka A. Fibrillogenic nuclei composed of P301L mutant tau induce elongation of P301L tau but not wild-type tau. The Journal of biological chemistry. 2007;282(28):20309-20318. doi:10.1074/jbc.M611876200

83. Barghorn S, Zheng-Fischhöfer Q, Ackmann M, et al. Structure, microtubule interactions, and paired helical filament aggregation by tau mutants of frontotemporal dementias. Biochemistry. 2000;39(38):11714-11721. doi:10.1021/bi000850r 


\section{Figure Legends}

Fig 1. Tau-dependent Gene expression. (A) Schematic representation of experimental plan, from Tet induction in WT and P301L Tau IHEK to RNA isolation, sequencing to gene expression analysis. (B) Volcano Plot for Down- and Up-regulated gene in WT Tau iHEK. (C) Volcano Plot for Down- and Upregulated gene in P301L Tau iHEK. (D) Gene Lists of Down-Regulated (Red Boxes) and Up-Regulated (Green Boxes) Genes in WT Tau iHEK. (E) Gene Lists of Down-Regulated (Red Boxes) and Up-Regulated (Green Boxes) Genes in P301L Tau iHEK.

Fig 2. Up- and Down regulated genes in WT Tau iHEK Gene Ontology. Left Column (Green) Upregulated genes analyzed by Enrich GO and divided by Biological Process, Molecular Function and Cellular Component. Right Column (Blue) Down-regulated genes analyzed by Enrich $\mathrm{GO}$ and divided by Biological Process, Molecular Function and Cellular Component. Grey bars represent not significant correlation.

Fig 3. WT tau modulates gene expression of chromatin organization and remodeling factors. (A) Enrichment plot for GO Chromatin organization. (B) Enrichment plot for GO Chromatin remodeling. (C) Enrichment plot for GO-Covalent Chromatin modification. (D) IB of Up-regulated genes: RCC1, DNAJC2 and Histone 1.2 (red box) and Down-regulated genes: SMARCC1, SMARCA5 and HMGB1 (blue box) in cytoplasm and nuclear fractions from WT and P301L Tau iHEK. Histone 3 and $\beta$-Actin has been used as loading control for nuclear and cytoplasmatic fractions, respectively. (E) representative Tau 13 (magenta) and Histone 1.2 (green) Co-IF of control (-Tet) and treated WT Tau iHEK. (F) Histone 1.2 integrated density quantification in control and + Tet cells (Unpaired t-test, $p<0.0001,{ }^{* * * *}$ ). (G) representative Tau 13 (magenta) and Ki67 (green) Co-IF of control (-Tet) and treated WT Tau iHEK. (H) Ki67 integrated density quantification in control and +Tet cells (Unpaired t-test, $p<0.0001,{ }^{* * * *}$ ). (I) representative Tau 13 (magenta) and SMARCC1 (green) Co-IF of control (-Tet) and treated WT Tau iHEK. (J) SMARCC1 integrated density quantification in control and +Tet cells (Unpaired t-test, $\left.p<0.0001,{ }^{* * * *}\right)$. (K) representative Tau 13 (magenta) and SMARCA5 (green) Co-IF of control (-Tet) and treated WT Tau iHEK. (L) SMARCA5 integrated density quantification in control and + Tet cells (Unpaired t-test, $p<0.0001,{ }^{* * * *}$ ).

Fig 4. Tau nuclear shuttling. (A) GWAS GO-Histone Binding heat map in WT Tau. (B) GWAS GONucleosome organization heat map in WT Tau. (C) Enrichment plot for GO Histone Binding. (D) Enrichment plot for GO Nucleosome Organization. (E) Immunoblot (IB) with Tau13 (1:1000) and $\beta$-Actin () of cytoplasm and nuclear fraction from WT (left panel) and P301L (right panel) Tau induced with Tet. (F) Relative density of nuclear monomeric Tau $\left(\mathrm{mTau}_{\mathrm{N}}\right.$, normalized with Histone3). Unpaired $t$-test has been performed to compare column means ((-) WT Tau vs WT Tau ***, $p=0.0009,(-)$ p301I Tau vs P301L Tau *, $p=0.0169$, WT Tau vs P301L Tau $\left.{ }^{* *}, p=0.0065\right)$. (G) Schematic model on Tau nuclear import in the two iHEK cell lines.

Fig 5. RNA metabolism, chromatin organization and HNRNPs precursor's display shortened APAs in the presence of WT tau. (A) Enrich-GO Biological Process of WT Tau shortened APAs ( $p$-value reported). (B) Partial list of biological process genes with shortened APAs upon presence of WT Tau (mRNA processing, RNA splicing, chromatin remodeling and regulation of response to DNA damage). (C) The Cellular Components scatterplot is organized so that similar gene sets are clustered together. The larger blue points represent significantly enriched terms - the darker the blue, the more significant the term and the smaller the $p$-value. The gray points are not significant. Plots has been generated and downloaded using scatter plot visualization Appyter. (D) Enrich-GO Cellular Component of WT Tau shortened APAs ( $p$ value reported). 
bioRxiv preprint doi: https://doi.org/10.1101/2021.07.16.452616; this version posted July 16, 2021. The copyright holder for this preprint (which was not certified by peer review) is the author/funder, who has granted bioRxiv a license to display the preprint in perpetuity. It is made available under aCC-BY 4.0 International license.

Fig 6. RNA processing and splicing precursor's display lengthened APAs in presence of WT tau. (A) Enrich-GO Biological Process of WT Tau lengthened APAs (p-value reported). (B) Partial list of biological process genes with lengthened APAs upon presence of WT Tau negative control of gene expression, chromatin remodeling, nucleosome organization, mRNA processing and regulation of transcription). (C) The Cellular Components scatterplot of lengthened APAs in WT Tau is organized so that similar gene sets are clustered together. The larger blue points represent significantly enriched terms - the darker the blue, the more significant the term and the smaller the $p$-value. The gray points are not significant. Plots has been generated and downloaded using scatter plot visualization Appyter. (d) Enrich-GO Cellular Component of WT Tau lengthened APAs ( $p$-value reported).

Fig 7. Mutant P301L Tau modulates APAs associated with spliceosome and nuclear chromatin. (A) Scatterplot of gene clusters from lengthened mRNA precursors upon P301L Tau expression. (B) Scatterplot of gene clusters from shortened mRNA precursors upon P301L Tau expression. (C) Model for nuclear Tau activity to transcriptional and post-transcriptional levels. 
Enrichment plot: GO_CHROMATIN_ORGANIZATION

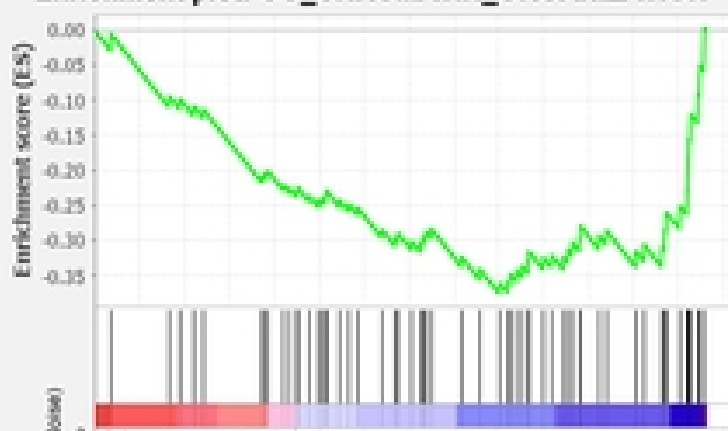

bioRxiv preprint doi: https://doi.org/10.1101/2021.07 章.

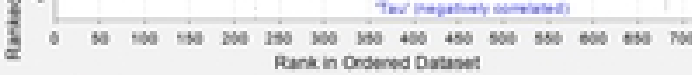

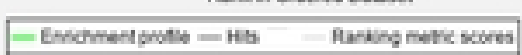

Enrichment plot: GO CHROMATIN_REMODELING

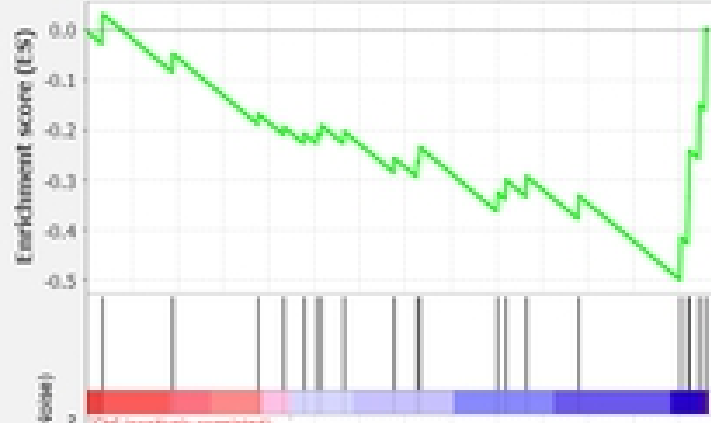

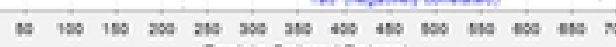

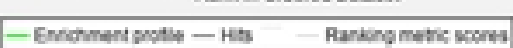

C

GO COVALENT CHROMATIN_MODIFICATION

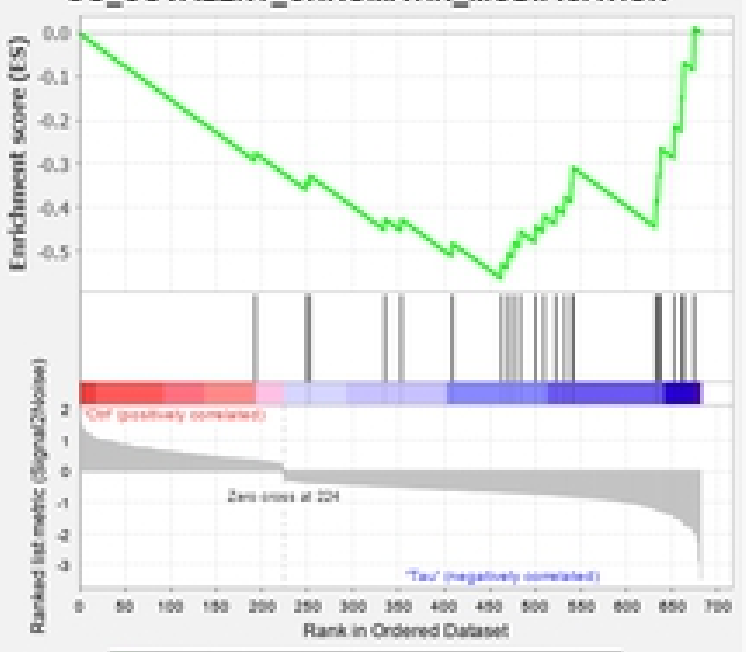

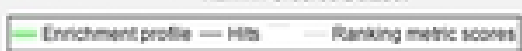

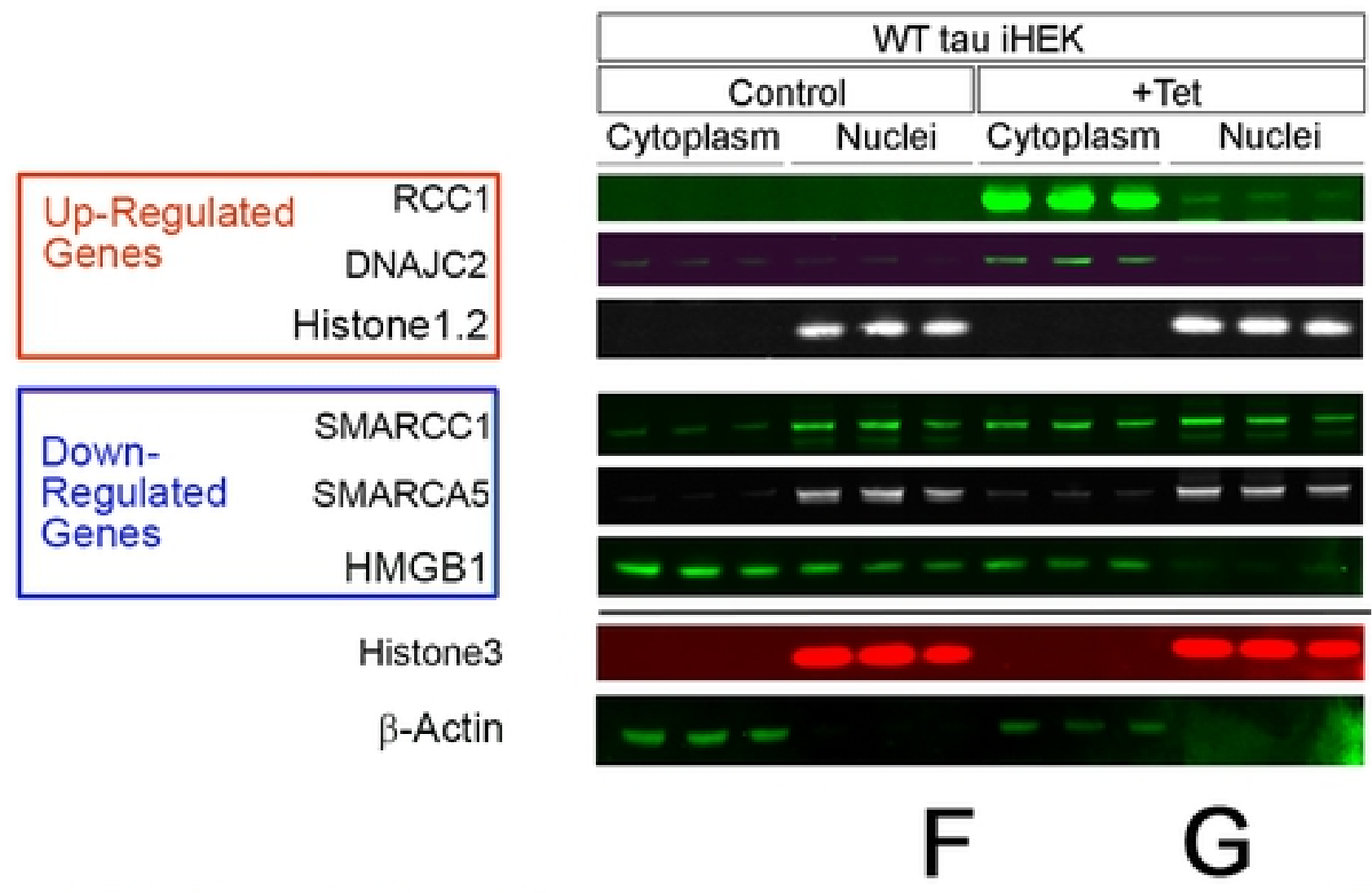

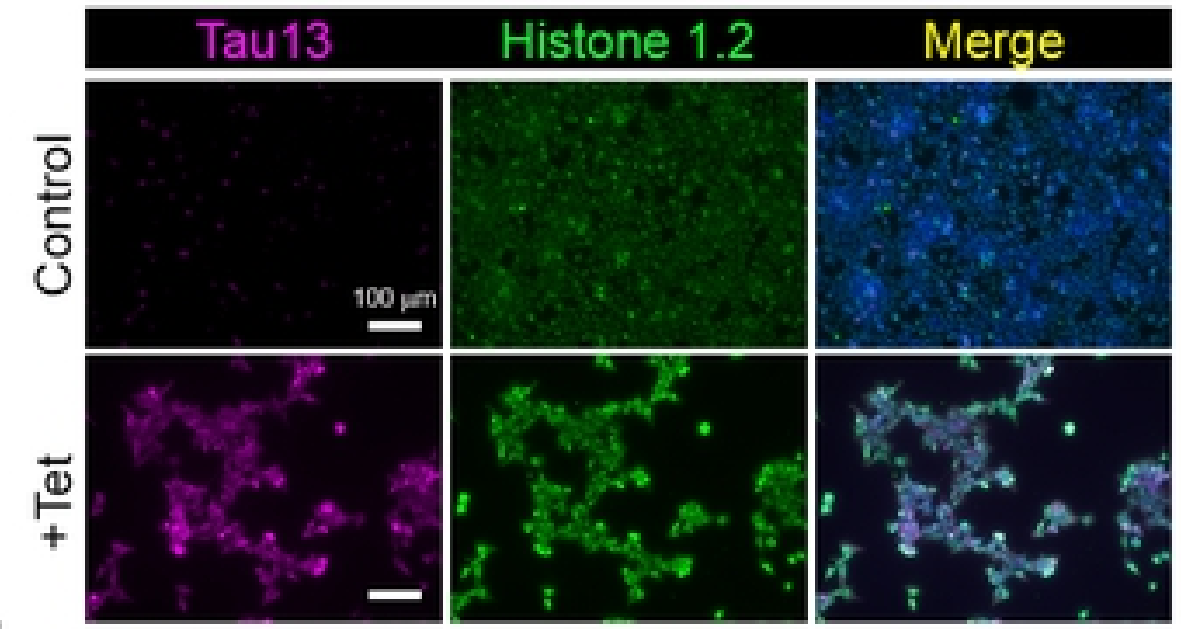

Tau13

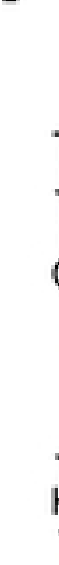

SMARCC1

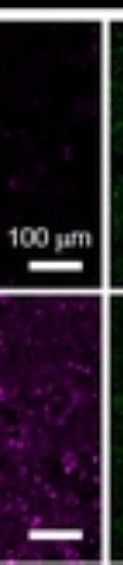

Merge

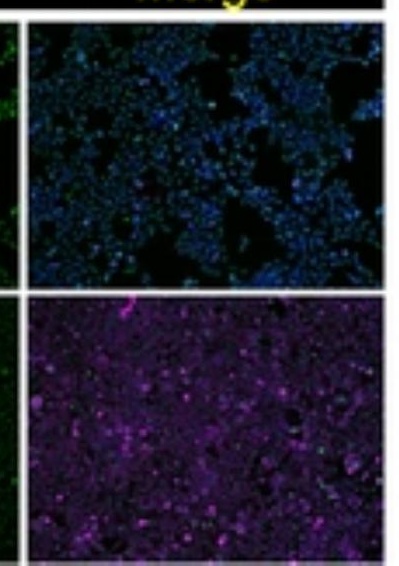

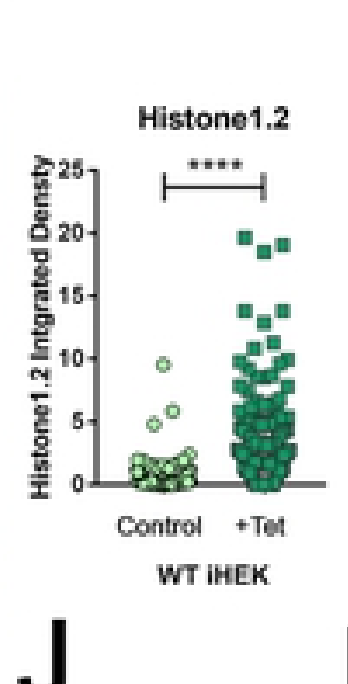

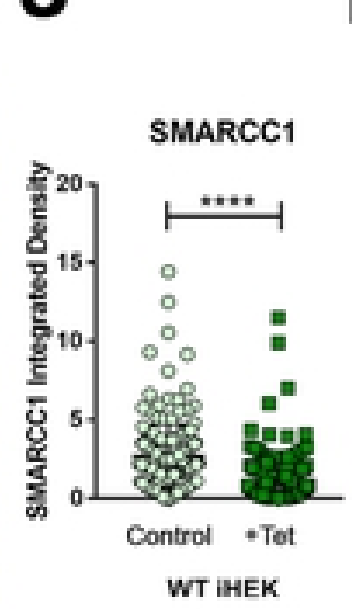

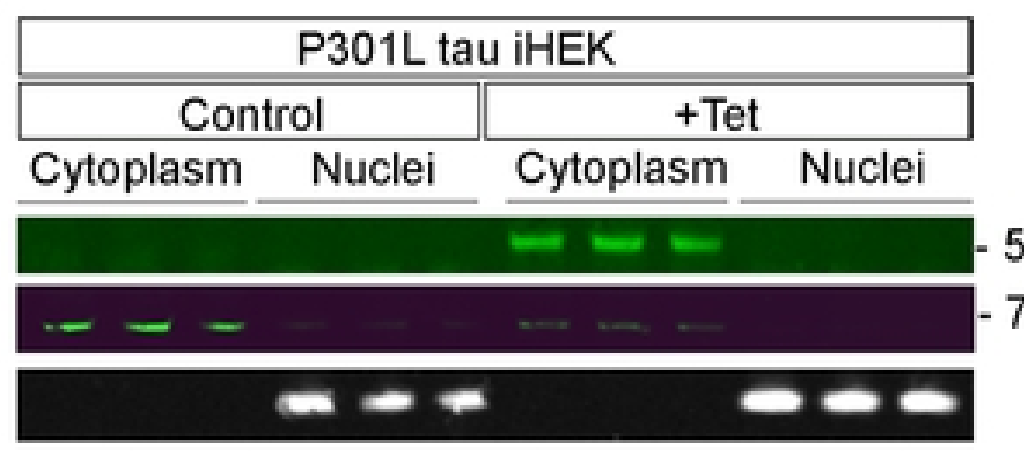

$50 \mathrm{kDa}$

$75 \mathrm{kDa}$

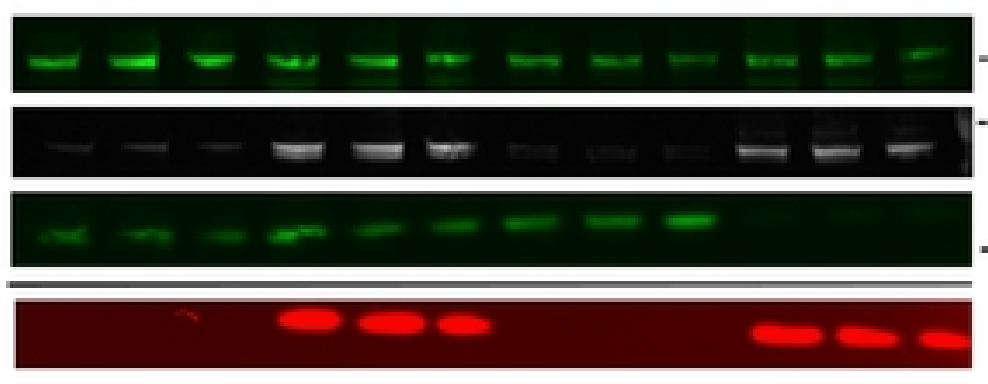

$150 \mathrm{kDa}$ $150 \mathrm{kDa}$

$-25 \mathrm{kDa}$
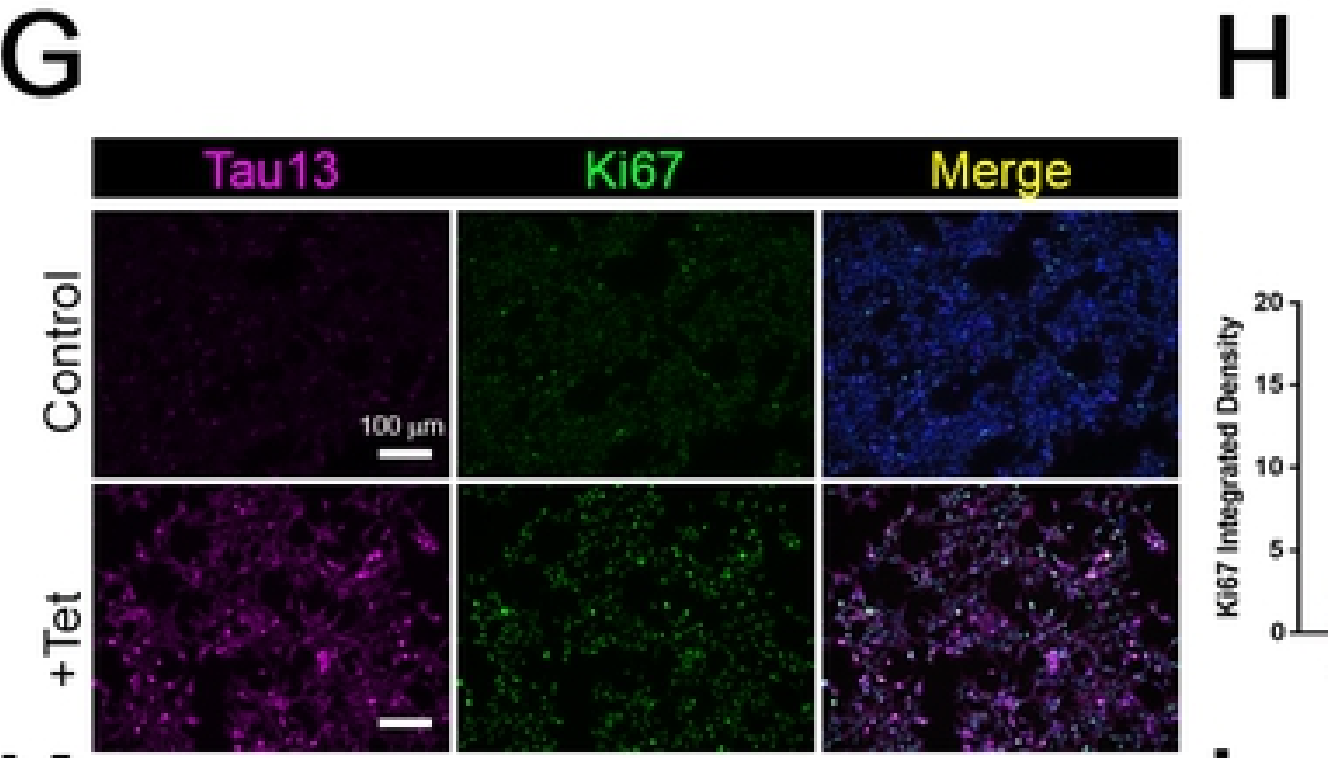

$\mathrm{K}$

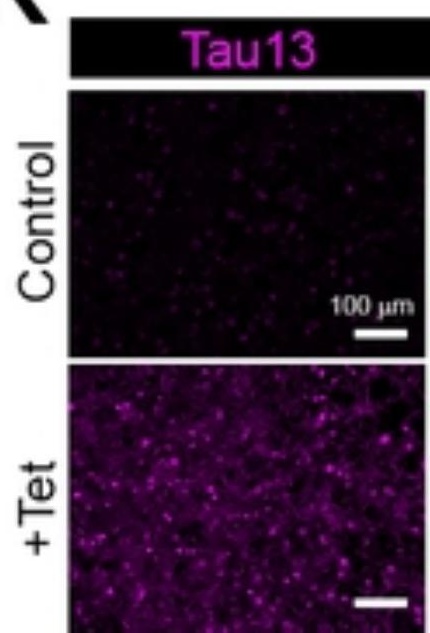

Merge
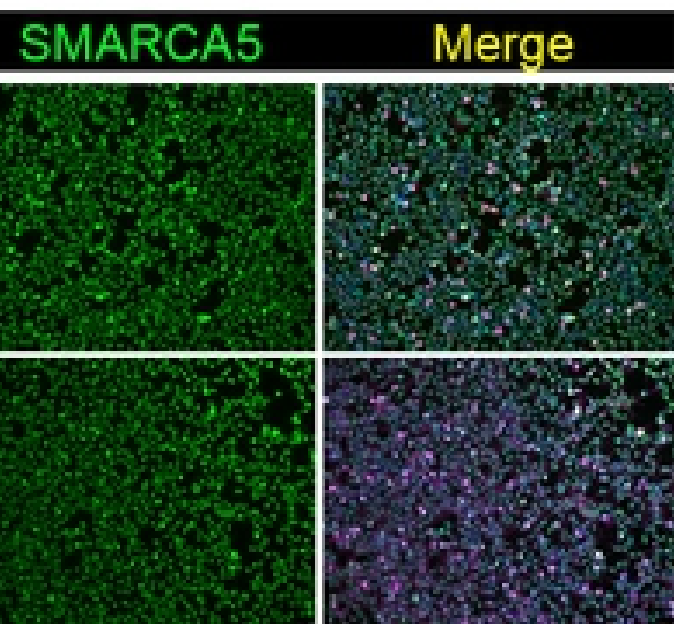

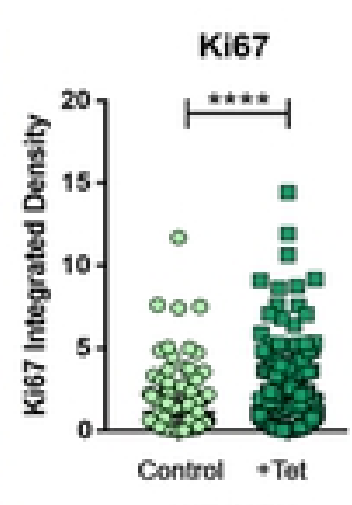

WT IHEK
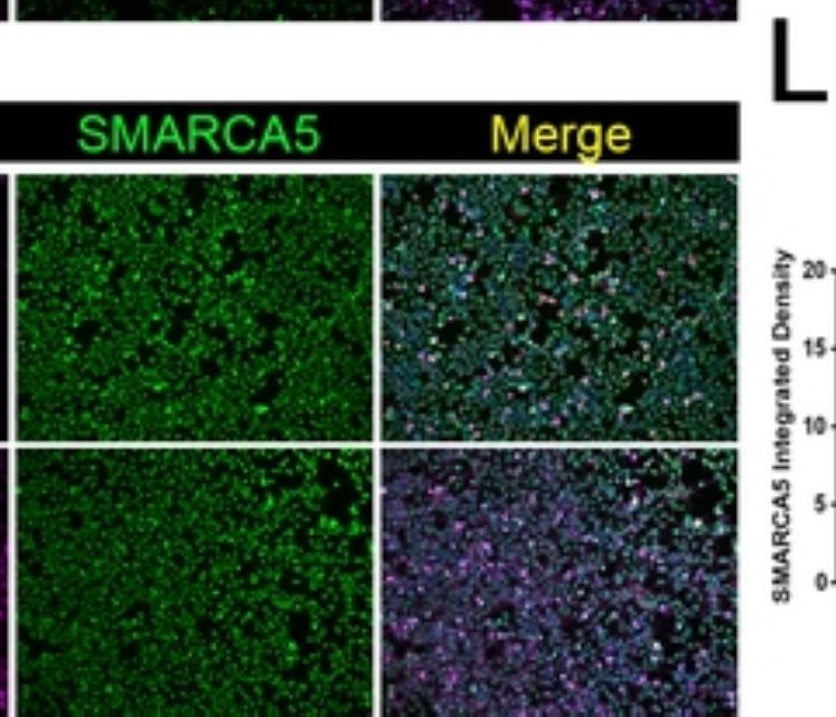

SMARCA5

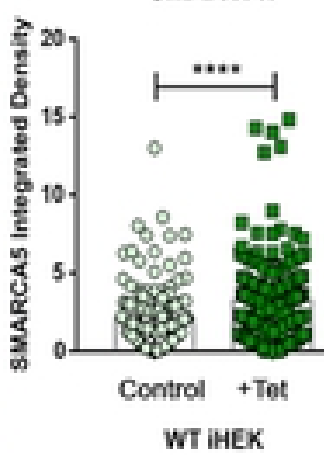


Enrichment plot: GO_HISTONE_BINDING

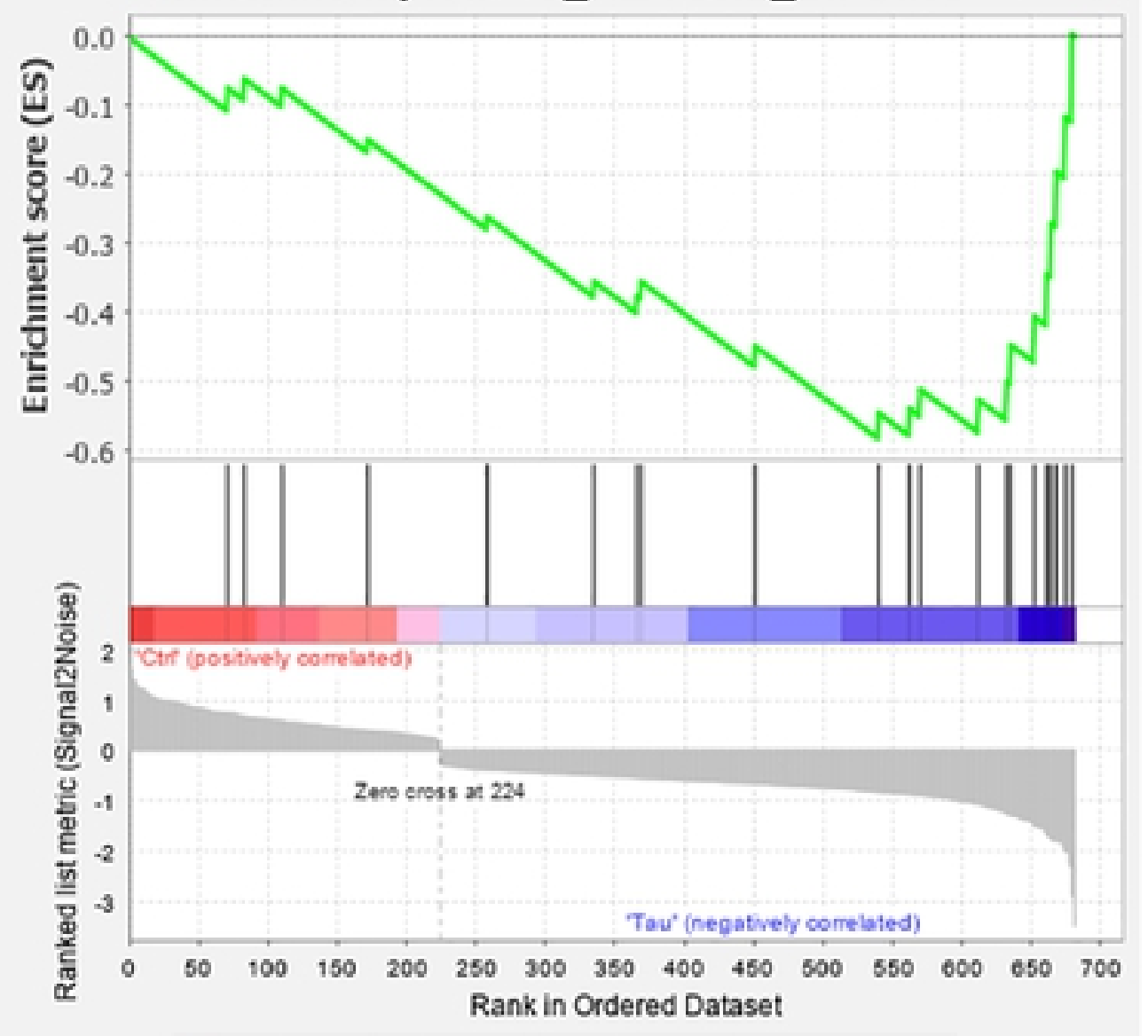

- Enrichment profile - Hits - - Ranking metric scores

bioRxiv preprint doi: https://doi.org/10.1101/2021.07.16.452616; this version posted July 16,2021 . The copyright holder for this preprint (which
was not certified by peer review) is the author/funder, who has granted bioRxiv a license to display the preprint in perpetuity. It is made
Enrichment plot: GO_NUCLEOSOME_ORGANIZATION

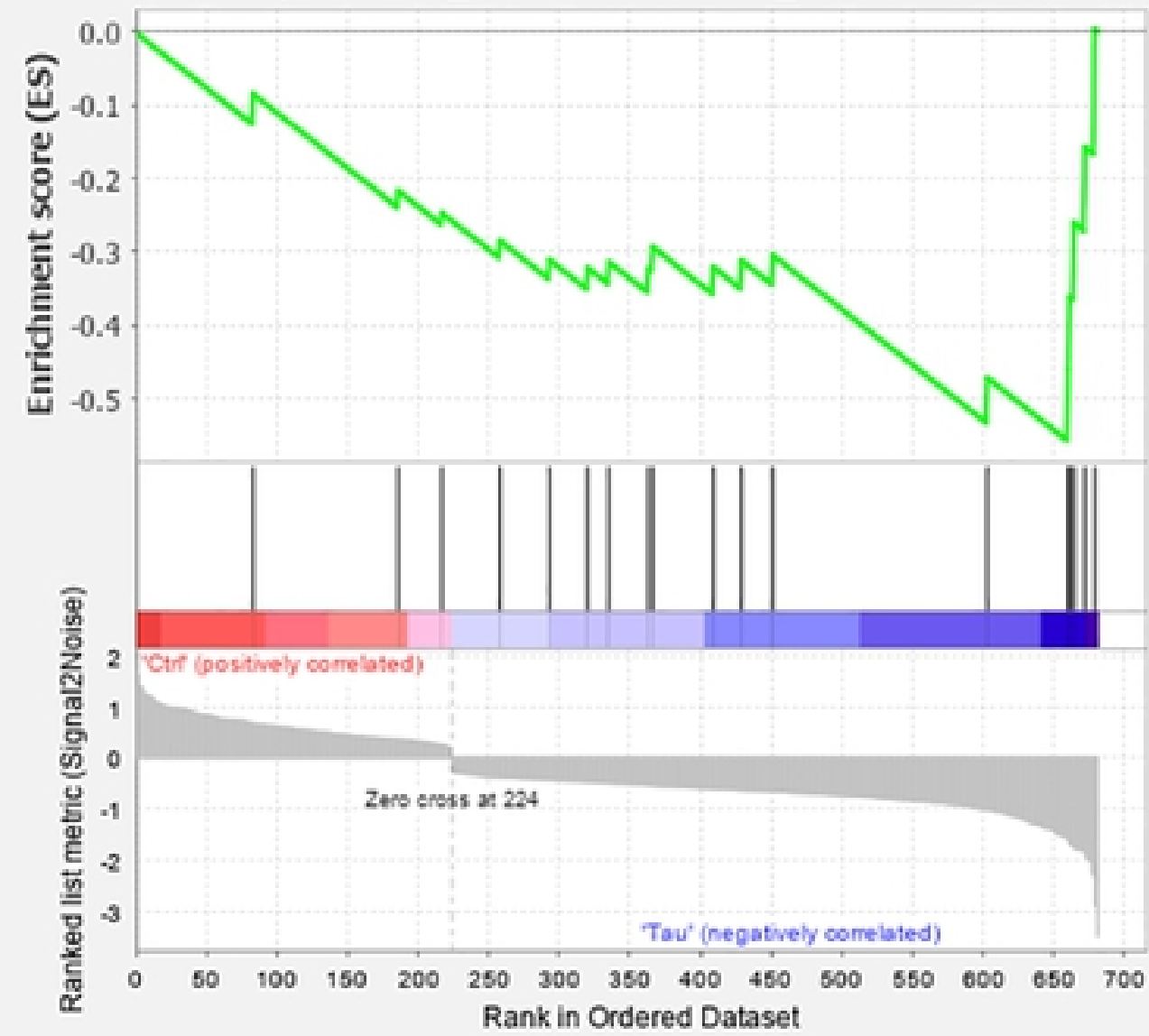
Rank in Ordered Dataset

\begin{tabular}{|c|}
\hline \multicolumn{2}{|c|}{ available under aCC-BY 4.0 International license. } \\
\hline WT Tau iHEK \\
\hline Control \\
\hline
\end{tabular}

Cytoplasm Nuclei Cytoplasm Nuclei

Tau13

$\beta$-Actin

Histone3
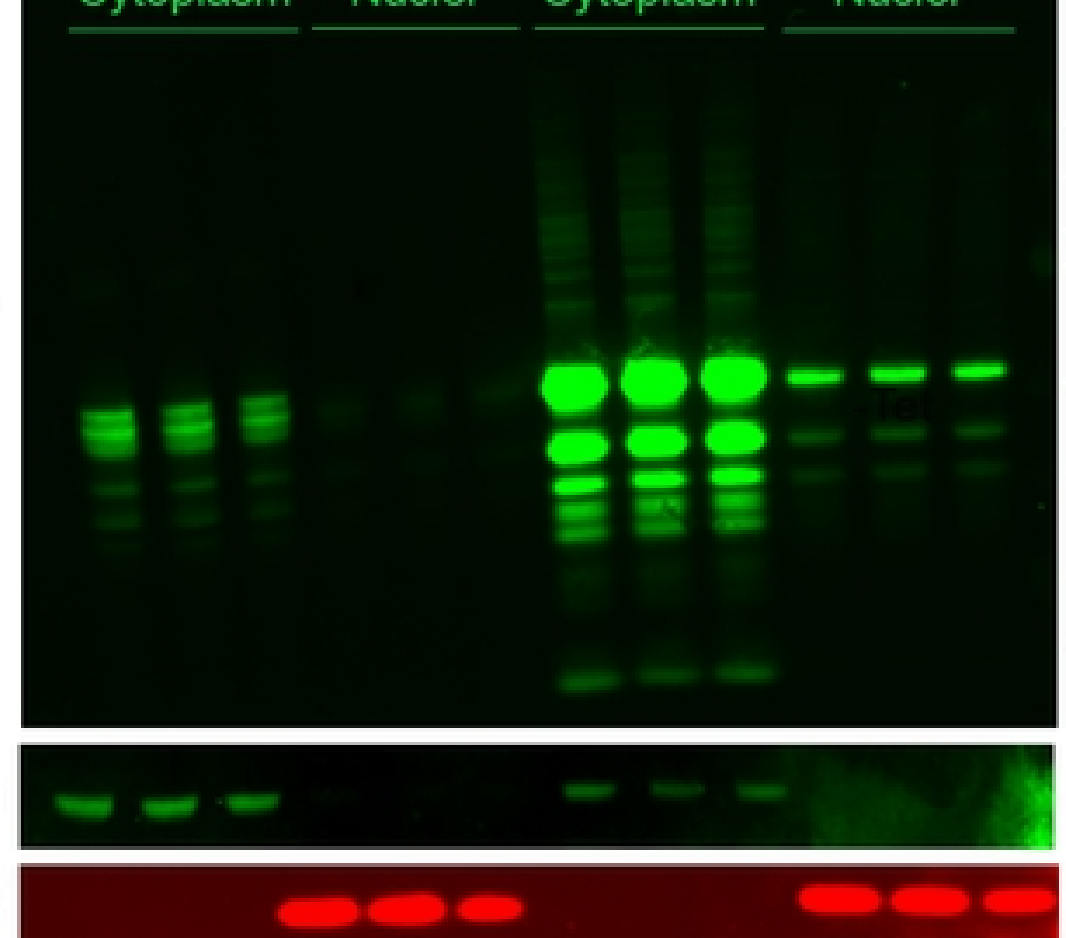

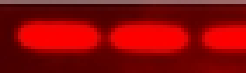

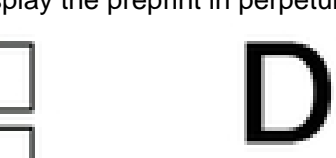

$-250 \mathrm{kDa}$

$-150 \mathrm{kDa}$

$-100 \mathrm{kDa}$
$-75 \mathrm{kDa}$

$-50 \mathrm{kDa}$

$-37 \mathrm{kDa}$

$-25 \mathrm{kDa}$

$-20 \mathrm{kDa}$

$-50 \mathrm{kDa}$

$-20 \mathrm{kDa}$

$-15 \mathrm{kDa}$

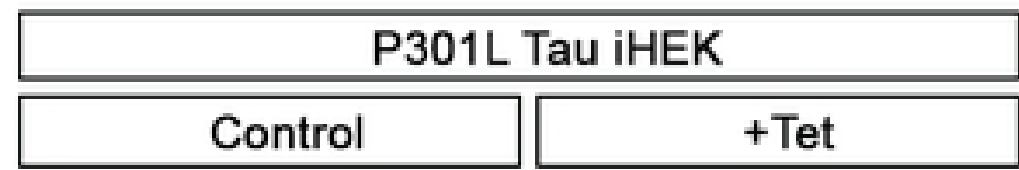

\section{Cytoplasm Nuclei Cytoplasm Nuclei}

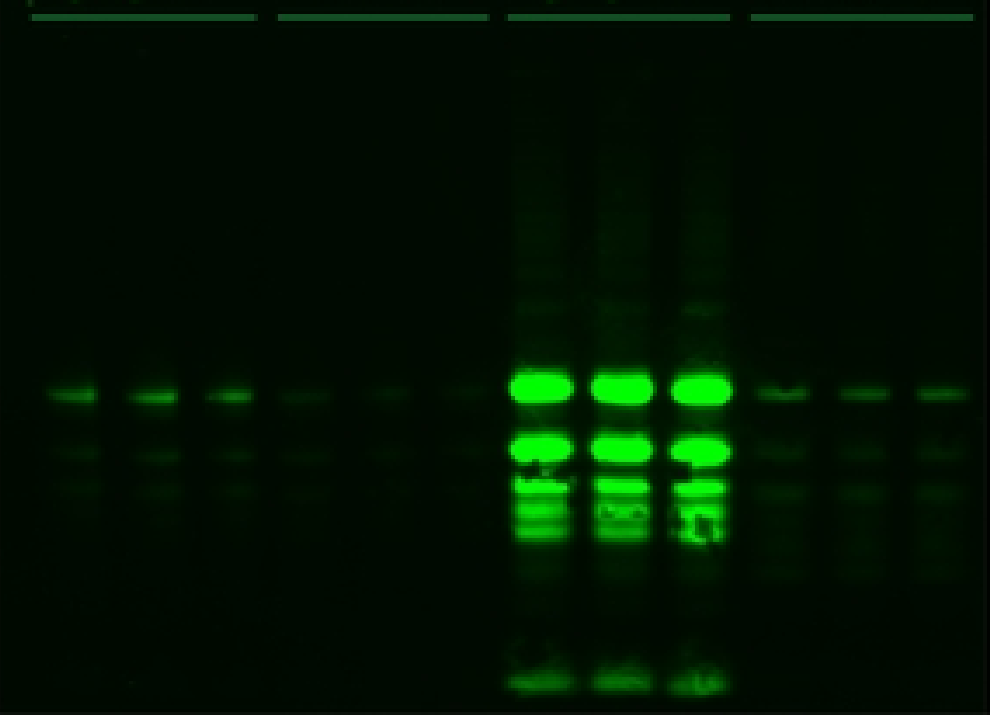

$250 \mathrm{kDa}$ $150 \mathrm{kDa}$ $100 \mathrm{kDa}$ $50 \mathrm{kDa}$ $37 \mathrm{kDa}$ $25 \mathrm{kDa}$ $20 \mathrm{kDa}$

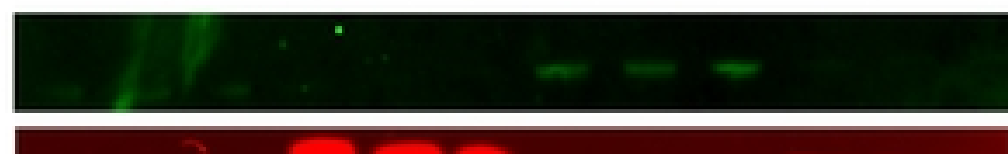

$50 \mathrm{kDa}$ $20 \mathrm{kDa}$ $-15 \mathrm{kDa}$

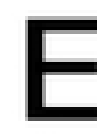

\section{$\mathrm{mTau}_{\mathrm{N}}$}

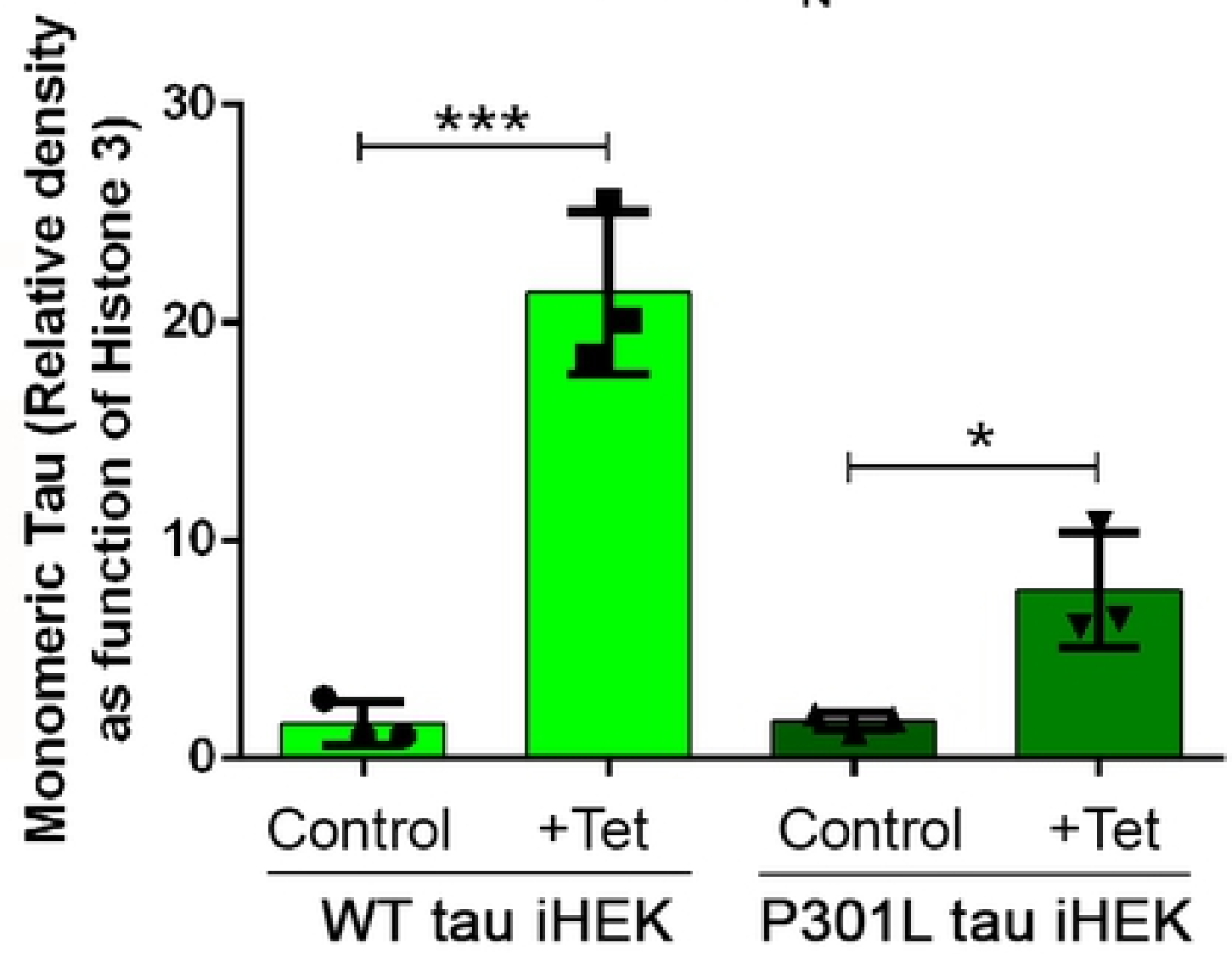

F wт таu

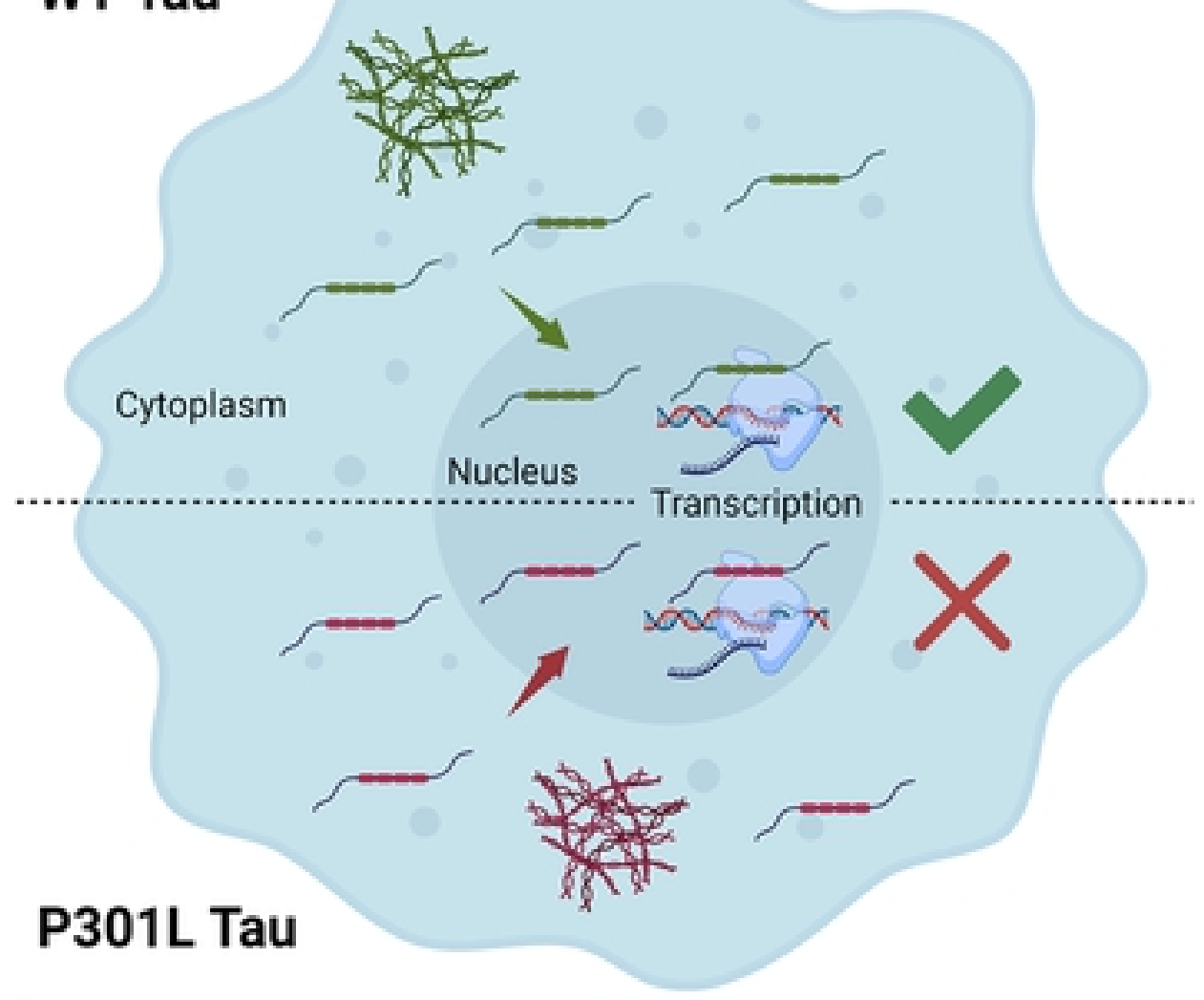




\section{Lengthened APAs Genes B}

WDR60 SLC16A1

SRSF7 TET1

DEGS1

THOC2

ARID4B

HMGN2

HUWE1

HNRNPF

FASN

JPT1

EGR1
Nuclear speckle/body

Granules

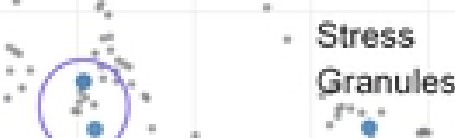

bioRxiv preprint doi: https://doi.org/10.1101/2021.07*16.452616; this versiohlposted July 16, 2021. The copyright holder for this preprint (which" ,

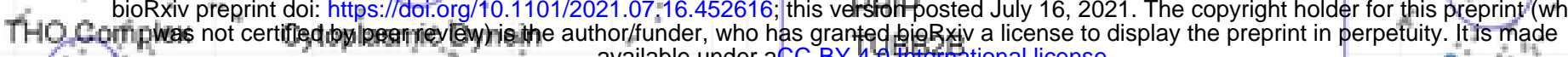

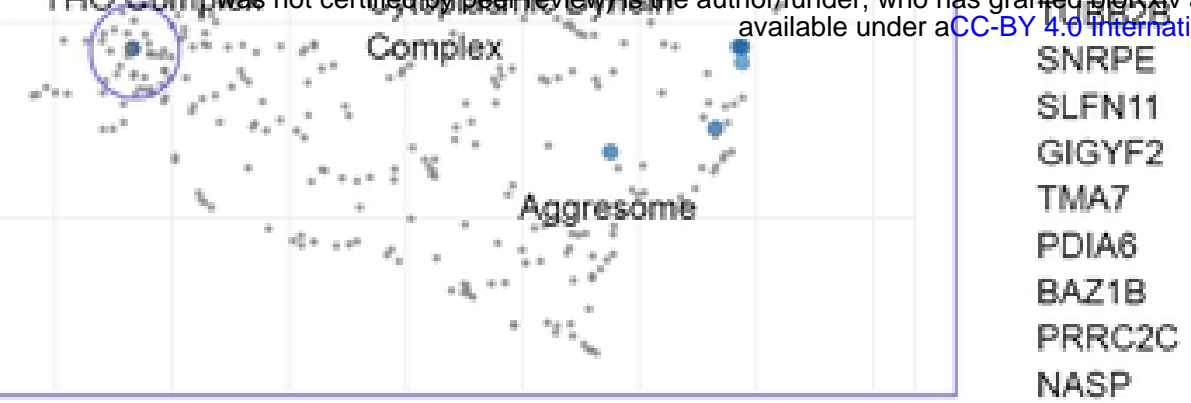

Scatterplot of gene clusters

from lengthened mRNA precursors
Shortened APAs Genes

RAB13 SMC1A

NEFL PMAIP1

EIF3A H2AFY

UBE2G2

$\mathrm{DBI}$

HIST1H1E

PABPC1

WDR5

ACAT2

SHMT2

SRSF4

RPL22

GUSBP11

CLK3

CALM3

MYO6

IRS4

SENP3-EIF4A1

TOMM22

RBM39

ENTR1

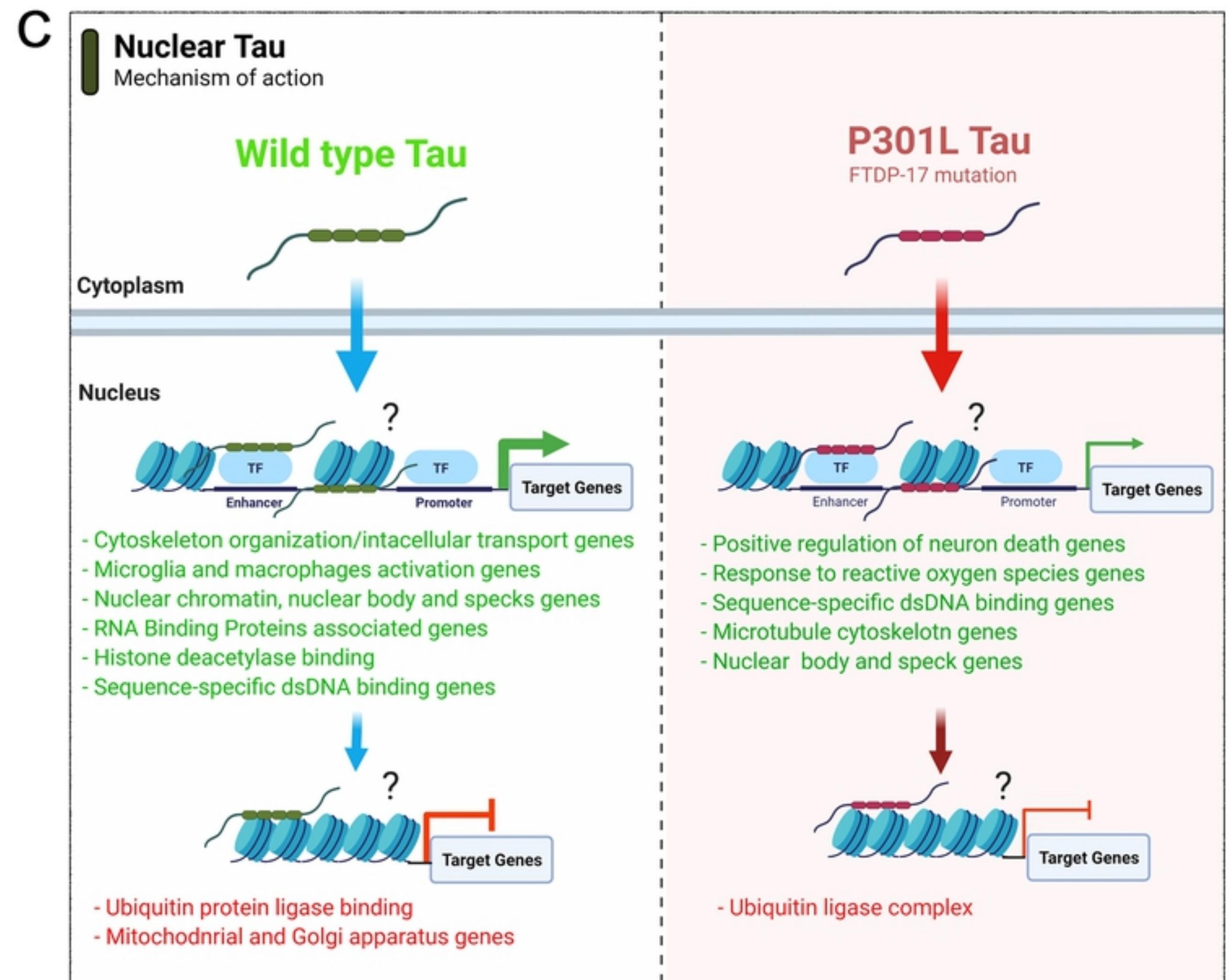




\section{Up-regulated Gene Ontology}

\section{Biological Process}

cyoskeleton-dependent intracellular transport (CO:0030705)

microglial cell activation (CO:0001774)

regulation of choskeleton organization (G0:0051493)

mitochondrion distribution (CO 0048311)

neurogenesis (CO.0022008)

positive regulation of cell death (GO:00 10942)

maturation of 5.85 reNA (CO.0000460)

macrophage activation (CO:0042: 16)

insulin receptor signaling pathway (CO-0008286)

maturation of LSU-rRNA (CO:-0000470)

\section{Molecular Function}

GTP binding (CO:0005525)

purine ribonucleoside binding (CO.0032550)

guarny ribonucleotide binding (CO. 0032561 )

RNA binding (C0.0003723)

racemase and epimerase activity, acting on carbohydrates and derivatives (CO.0016857)

double-stranded RNA binding (CO. 0003725)

histone deacetylase binding (CD.0042826)

purine ribonucleoside triph osphate binding (CO. 0035639 )

sequence-specifil: double-stranded DNA binding (CO: 1990837)

transcriptional repressor activity, RNA polymerase II transcription factor binding (GO:0001191)

\section{Cellular Component}

cytoskeleton (C0.000585)

polymeric Moskeletal fiber (CO.0099513)

nuclear chromatin $(60.0000790)$

microtubule croskeleton (CO-0015630)

nuclear chromosome part (CO.0044454)

microtubule (CO.0005874)

preribos ome, large subunit precursor (GO:0030687)

nuclear speck (CO:0016607)

encoplasmic vesicle (GO.003 1410)

nuclear body (CO:0016604)

\section{Down-regulated Gene Ontology}

\section{Biological Process}

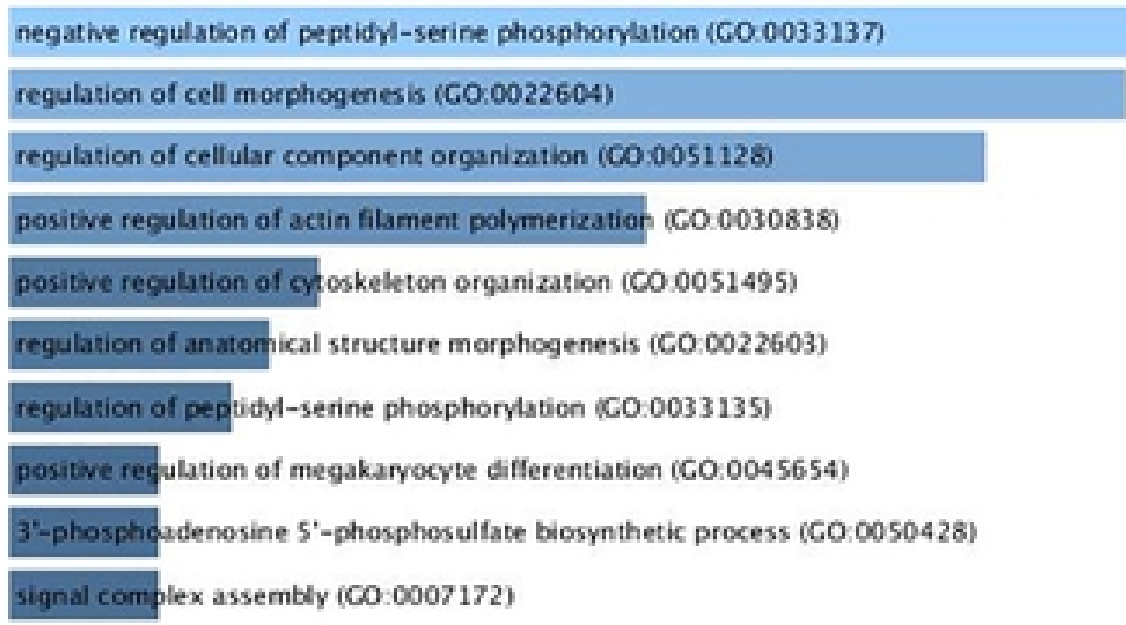

\section{Molecular Function}

ubiquitin protein ligase binding (CO:0031625)

ubiquitin-like protein ligase binding (CO 0044389)

acetylcholine receptor regulator activity (CO.0030548)

RNA polymerase II transcription faxtor binding (GO:0001055)

cytoskeletal adaptor axtivity (CO.0008093)

co-SMAD binding (CO.0070410)

pseudouricine symthase axtivisy (CO00009952)

oxalate transmembrane transporter actwity (CO.0019531)

sulfate transmembrane transporter activity (CO.0015116)

transaminase activity (CO:0008483)

\section{Cellular Component}

axon initial segment (CO.0043194)

node of Ramier (CO.0033268)

main axon (CO.0044304)

SCF ubiquitin ligase complex (CO.0019005)

coated vesicle (CO.0030135)

ribosome (GO:0005840)

perinuclear region of cytoplasm (CO:0048471)

trans-Colgi network membrane (CO:0032588)

dathrin-coated vesicle (GO.0030136)

Golgi membrane (CO:0000139) 


\begin{tabular}{|c|c|c|c|c|c|}
\hline \multicolumn{6}{|c|}{ Supplemental Table 1. Up-Regulated Genes by WT Tau } \\
\hline Term & P-value & $\begin{array}{l}\text { Adjusted } \\
\text { P-value }\end{array}$ & $\begin{array}{l}\text { Odds } \\
\text { Ratio }\end{array}$ & $\begin{array}{l}\text { Combined } \\
\text { Score }\end{array}$ & Genes \\
\hline $\begin{array}{l}\text { cytoskeleton } \\
\text { (GO:0005856) }\end{array}$ & $1.73 E-05$ & $\begin{array}{l}0.0077356 \\
74\end{array}$ & $\begin{array}{l}4.80769 \\
2308\end{array}$ & 52.70303651 & $\begin{array}{l}\text { TUBA1B;SAP30BP;TUBB2B;TUBA } \\
\text { 1A;TMOD3;MAP7;TARS;TACC1; } \\
\text { MAPT;CLU;RHOQ }\end{array}$ \\
\hline $\begin{array}{l}\text { polymeric cytoskeletal } \\
\text { fiber (GO:0099513) }\end{array}$ & 4.34E-04 & $\begin{array}{l}0.0966945 \\
62\end{array}$ & $\begin{array}{l}6.17030 \\
0288\end{array}$ & 47.77891745 & $\begin{array}{l}\text { TUBA1B;TUBB2B;TUBA1A;TUBB } \\
\text { 2A;MAPT;RHOQ }\end{array}$ \\
\hline $\begin{array}{l}\text { nuclear chromatin } \\
\text { (GO:0000790) }\end{array}$ & $8.81 E-04$ & $\begin{array}{l}0.1309033 \\
68\end{array}$ & $\begin{array}{l}5.38986 \\
705\end{array}$ & 37.91772839 & $\begin{array}{l}\text { MEF2A;ZEB2;ANP32E;SUDS3;HIS } \\
\text { T2H2AC;HIST1H1C }\end{array}$ \\
\hline $\begin{array}{l}\text { microtubule } \\
\text { cytoskeleton } \\
(\mathrm{GO}: 0015630)\end{array}$ & 0.001616162 & $\begin{array}{l}0.1802021 \\
06\end{array}$ & $\begin{array}{l}4.10028 \\
1162\end{array}$ & 26.35538067 & $\begin{array}{l}\text { TUBA1B;TUBB2B;TUBA1A;TUBB } \\
\text { 2A;MAP7;TACC1;MAPT }\end{array}$ \\
\hline $\begin{array}{l}\text { nuclear chromosome } \\
\text { part (GO:0044454) }\end{array}$ & 0.001713127 & $\begin{array}{l}0.1528109 \\
38\end{array}$ & $\begin{array}{l}4.05844 \\
1558\end{array}$ & 25.84997914 & $\begin{array}{l}\text { MEF2A;ZEB2;POLE3;ANP32E;SU } \\
\text { DS3;CDC73;HIST2H2AC }\end{array}$ \\
\hline 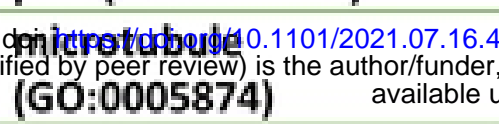 & 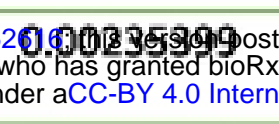 & 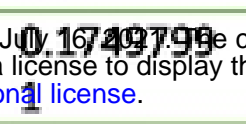 & $\begin{array}{l}\text { oyglat holdes fo } \\
\text { preprint in perp } \\
5411\end{array}$ & $\begin{array}{l}\text { Bzargati69ogen } 4 \\
\text { ity. It is made }\end{array}$ & $\begin{array}{l}\text { TUBA1B;TUBB2B;TUBA1A;TUBB } \\
\text { 2A;MAPT }\end{array}$ \\
\hline $\begin{array}{l}\text { preribosome, large } \\
\text { subunit precursor } \\
\text { (GO:0030687) }\end{array}$ & 0.00580801 & $\begin{array}{l}0.3700532 \\
18\end{array}$ & $\begin{array}{l}17.4825 \\
1748\end{array}$ & 90.00904291 & RRP15;FTSJ3 \\
\hline $\begin{array}{l}\text { nuclear speck } \\
\text { (GO:0016607) }\end{array}$ & 0.009908573 & $\begin{array}{l}0.5524029 \\
27\end{array}$ & $\begin{array}{l}3.83906 \\
6339\end{array}$ & 17.71481484 & $\begin{array}{l}\text { USP36;CARMIL1;GTF2H2C;BAZ2 } \\
\text { A;MAPT }\end{array}$ \\
\hline $\begin{array}{l}\text { cytoplasmic vesicle } \\
\text { (GO:0031410) }\end{array}$ & 0.015007567 & $\begin{array}{l}0.7437083 \\
22\end{array}$ & $\begin{array}{l}4.22832 \\
981\end{array}$ & 17.75560565 & TFRC;ANP32E;CLCN3;RHOQ \\
\hline $\begin{array}{l}\text { nuclear body } \\
\text { (GO:0016604) }\end{array}$ & 0.019146203 & $\begin{array}{l}0.8539206 \\
72\end{array}$ & $\begin{array}{l}2.57428 \\
6555\end{array}$ & 10.18297877 & $\begin{array}{l}\text { USP36;CARMIL1;GTF2H2C;BAZ2 } \\
\text { A;MAPT;SUDS3;SENP2 }\end{array}$ \\
\hline $\begin{array}{l}\text { axolemma } \\
\text { (GO:0030673) }\end{array}$ & 0.026114353 & 1 & $\begin{array}{l}37.8787 \\
8788\end{array}$ & 138.0784165 & MAPT \\
\hline nucleolus (GO:0005730) & 0.029395392 & 1 & $\begin{array}{l}2.35341 \\
5815\end{array}$ & 8.300303054 & $\begin{array}{l}\text { USP36;NOM1;ZEB2;BAZ2A;PHF6 } \\
\text {;PELP1;FTSJ3 }\end{array}$ \\
\hline $\begin{array}{l}\text { messenger } \\
\text { ribonucleoprotein } \\
\text { complex (GO:1990124) }\end{array}$ & 0.030400721 & 1 & $\begin{array}{l}32.4675 \\
3247\end{array}$ & 113.4184725 & CPEB4 \\
\hline $\begin{array}{l}\text { spherical high-density } \\
\text { lipoprotein particle } \\
\text { (GO:0034366) }\end{array}$ & 0.034668438 & 1 & $\begin{array}{l}28.4090 \\
9091\end{array}$ & 95.50924912 & CLU \\
\hline $\begin{array}{l}\text { HFE-transferrin receptor } \\
\text { complex (GO:1990712) }\end{array}$ & 0.034668438 & 1 & $\begin{array}{l}28.4090 \\
9091\end{array}$ & 95.50924912 & TFRC \\
\hline $\begin{array}{l}\text { Cdc73/Paf1 complex } \\
\text { (GO:0016593) }\end{array}$ & 0.034668438 & $\begin{array}{l}0.9663827 \\
14\end{array}$ & $\begin{array}{l}28.4090 \\
9091\end{array}$ & 95.50924912 & CDC73 \\
\hline $\begin{array}{l}\text { apical dendrite } \\
\text { (GO:0097440) }\end{array}$ & 0.034668438 & $\begin{array}{l}0.9095366 \\
72\end{array}$ & $\begin{array}{l}28.4090 \\
9091\end{array}$ & 95.50924912 & CLU \\
\hline $\begin{array}{l}\text { chromatin silencing } \\
\text { complex (GO:0005677) }\end{array}$ & 0.034668438 & $\begin{array}{l}0.8590068 \\
57\end{array}$ & $\begin{array}{l}28.4090 \\
9091\end{array}$ & 95.50924912 & BAZ2A \\
\hline $\begin{array}{l}\text { Swr1 complex } \\
\text { (GO:0000812) }\end{array}$ & 0.038917584 & $\begin{array}{l}0.9135390 \\
84\end{array}$ & $\begin{array}{l}25.2525 \\
2525\end{array}$ & 81.97750232 & ANP32E \\
\hline chromatin (GO:0000785) & 0.041696789 & $\begin{array}{l}0.9298384 \\
01\end{array}$ & $\begin{array}{l}3.07125 \\
3071\end{array}$ & 9.758388048 & MEF2A;ZEB2;HIST2H2AC;PELP1 \\
\hline $\begin{array}{l}\text { preribosome } \\
\text { (GO:0030684) }\end{array}$ & 0.043179537 & $\begin{array}{l}0.9170511 \\
21\end{array}$ & $\begin{array}{l}6.06060 \\
6061\end{array}$ & 19.04477924 & RRP15;FTSI3 \\
\hline $\begin{array}{l}\text { proton-transporting V- } \\
\text { type ATPase complex } \\
\text { (GO:0033176) }\end{array}$ & 0.047360482 & $\begin{array}{l}0.9601261 \\
39\end{array}$ & $\begin{array}{l}20.6611 \\
5702\end{array}$ & 63.01584932 & ATP6V1D \\
\hline $\begin{array}{l}\text { ribonucleoprotein } \\
\text { granule (GO:0035770) }\end{array}$ & 0.04848675 & $\begin{array}{l}0.9402213 \\
22\end{array}$ & $\begin{array}{l}5.68181 \\
8182\end{array}$ & 17.19582226 & TUBA1A;MAPT \\
\hline
\end{tabular}




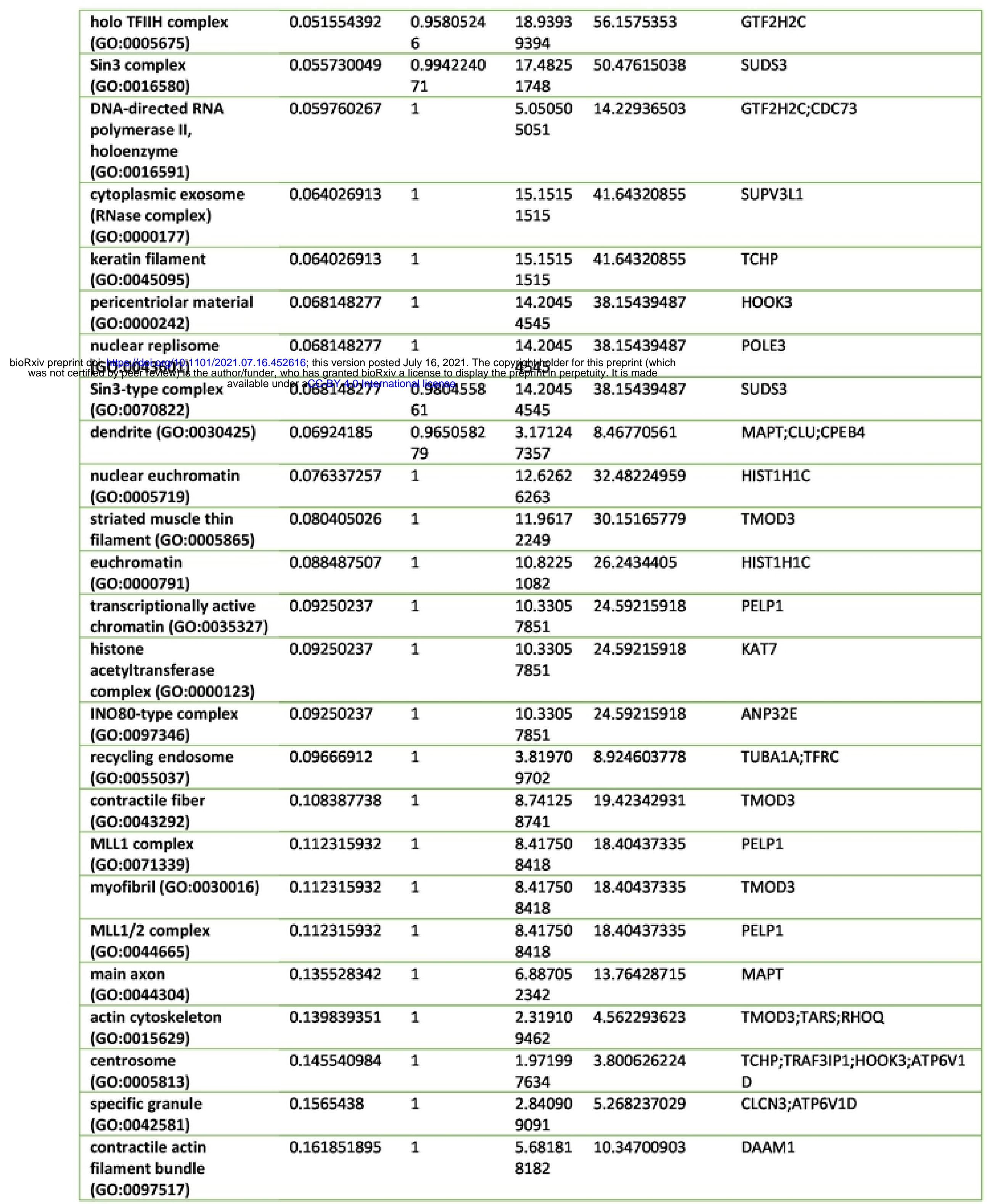




\begin{tabular}{|c|c|c|c|c|c|}
\hline $\begin{array}{l}\text { integral component of } \\
\text { Golgi membrane } \\
\text { (GO:0030173) }\end{array}$ & 0.161851895 & 1 & $\begin{array}{l}5.68181 \\
8182\end{array}$ & 10.34700903 & UBIAD1 \\
\hline $\begin{array}{l}\text { stress fiber } \\
\text { (GO:0001725) }\end{array}$ & 0.161851895 & 1 & $\begin{array}{l}5.68181 \\
8182\end{array}$ & 10.34700903 & DAAM1 \\
\hline $\begin{array}{l}\text { heterochromatin } \\
\text { (GO:0000792) }\end{array}$ & 0.165547132 & 1 & $\begin{array}{l}5.54323 \\
7251\end{array}$ & 9.969508533 & BAZ2A \\
\hline $\begin{array}{l}\text { cytoplasmic } \\
\text { ribonucleoprotein } \\
\text { granule (GO:0036464) }\end{array}$ & 0.172060346 & 1 & $\begin{array}{l}2.67379 \\
6791\end{array}$ & 4.705641744 & TUBA1A;MAPT \\
\hline $\begin{array}{l}\text { intermediate filament } \\
\text { (GO:0005882) }\end{array}$ & 0.183783091 & 1 & $\begin{array}{l}4.94071 \\
1462\end{array}$ & 8.369560635 & TCHP \\
\hline $\begin{array}{l}\text { microtubule organizing } \\
\text { center (GO:0005815) }\end{array}$ & 0.184397492 & 1 & $\begin{array}{l}1.79307 \\
8716\end{array}$ & 3.031489277 & $\begin{array}{l}\text { TCHP;TRAF3IP1;HOOK3;ATP6V1 } \\
\text { D }\end{array}$ \\
\hline $\begin{array}{l}\text { cis-Golgi network } \\
\text { (GO:0005801) }\end{array}$ & 0.187382719 & 1 & $\begin{array}{l}4.83558 \\
9942\end{array}$ & 8.097689209 & HОOKЗ \\
\hline 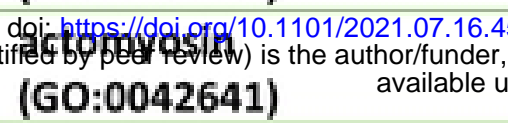 & 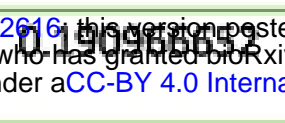 & 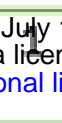 & 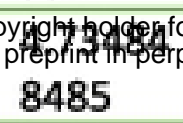 & 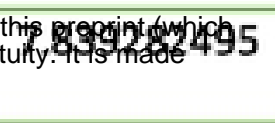 & DAAM1 \\
\hline $\begin{array}{l}\text { actin filament } \\
\text { (GO:0005884) }\end{array}$ & 0.215620364 & 1 & $\begin{array}{l}4.13223 \\
1405\end{array}$ & 6.339818153 & RHOQ \\
\hline $\begin{array}{l}\text { perinuclear region of } \\
\text { cytoplasm (GO:0048471) }\end{array}$ & 0.232031019 & 1 & $\begin{array}{l}1.80375 \\
1804\end{array}$ & 2.635072538 & GALNT6;TFRC;CLU \\
\hline PML body (GO:0016605) & 0.239531081 & 1 & $\begin{array}{l}3.66568 \\
915\end{array}$ & 5.238534082 & SENP2 \\
\hline $\begin{array}{l}\text { platelet alpha granule } \\
\text { lumen (GO:0031093) }\end{array}$ & 0.256167561 & 1 & $\begin{array}{l}3.39213 \\
0258\end{array}$ & 4.619821964 & CLU \\
\hline $\begin{array}{l}\text { nucleoplasm part } \\
\text { (GO:0044451) }\end{array}$ & 0.266189763 & 1 & $\begin{array}{l}1.67522 \\
8948\end{array}$ & 2.217242288 & GTF2H2C;KAT7;SUDS3 \\
\hline $\begin{array}{l}\text { intermediate filament } \\
\text { cytoskeleton } \\
\text { (GO:0045111) }\end{array}$ & 0.269217242 & 1 & $\begin{array}{l}3.20102 \\
4328\end{array}$ & 4.200501392 & SAP30BP \\
\hline $\begin{array}{l}\text { Iytic vacuole membrane } \\
\text { (GO:0098852) }\end{array}$ & 0.273570882 & 1 & $\begin{array}{l}1.95083 \\
8861\end{array}$ & 2.528666646 & DAGLB;ATP6V1D \\
\hline $\begin{array}{l}\text { nuclear periphery } \\
\text { (GO:0034399) }\end{array}$ & 0.291511782 & 1 & $\begin{array}{l}2.91375 \\
2914\end{array}$ & 3.591709949 & MAPT \\
\hline $\begin{array}{l}\text { clathrin-coated vesicle } \\
\text { membrane } \\
\text { (GO:0030665) }\end{array}$ & 0.300859484 & 1 & $\begin{array}{l}2.80583 \\
6139\end{array}$ & 3.370123323 & TFRC \\
\hline $\begin{array}{l}\text { phagocytic vesicle } \\
\text { (GO:0045335) }\end{array}$ & 0.307023439 & 1 & $\begin{array}{l}2.73822 \\
563\end{array}$ & 3.23338222 & CLCN3 \\
\hline $\begin{array}{l}\text { platelet alpha granule } \\
\text { (GO:0031091) }\end{array}$ & 0.328177166 & 1 & $\begin{array}{l}2.52525 \\
2525\end{array}$ & 2.813640594 & CLU \\
\hline $\begin{array}{l}\text { specific granule } \\
\text { membrane } \\
\text { (GO:0035579) }\end{array}$ & 0.331146544 & 1 & $\begin{array}{l}2.49750 \\
2498\end{array}$ & 2.76022545 & ATP6V1D \\
\hline $\begin{array}{l}\text { clathrin-coated vesicle } \\
\text { (GO:0030136) }\end{array}$ & 0.357293708 & 1 & $\begin{array}{l}2.27272 \\
7273\end{array}$ & 2.33908437 & TFRC \\
\hline $\begin{array}{l}\text { lysosomal membrane } \\
\text { (GO:0005765) }\end{array}$ & 0.367155241 & 1 & $\begin{array}{l}1.56201 \\
1871\end{array}$ & 1.565089849 & DAGLB;ATP6V1D \\
\hline $\begin{array}{l}\text { nuclear chromosome, } \\
\text { telomeric region } \\
\text { (GO:0000784) }\end{array}$ & 0.376929429 & 1 & $\begin{array}{l}2.12404 \\
418\end{array}$ & 2.072424172 & CDC73 \\
\hline $\begin{array}{l}\text { endocytic vesicle } \\
\text { (GO:0030139) }\end{array}$ & 0.379685681 & 1 & $\begin{array}{l}2.10437 \\
7104\end{array}$ & 2.037903041 & CLCN3 \\
\hline $\begin{array}{l}\text { chromosome, telomeric } \\
\text { region (GO:0000781) }\end{array}$ & 0.422181171 & 1 & $\begin{array}{l}1.83284 \\
4575\end{array}$ & 1.580499895 & CDC73 \\
\hline
\end{tabular}




\begin{tabular}{|c|c|c|c|c|c|}
\hline $\begin{array}{l}\text { microtubule organizing } \\
\text { center part } \\
\text { (GO:0044450) }\end{array}$ & 0.427286491 & 1 & $\begin{array}{l}1.80375 \\
1804\end{array}$ & 1.533731156 & НООКЗ \\
\hline $\begin{array}{l}\text { late endosome } \\
\text { (GO:0005770) }\end{array}$ & 0.461796269 & 1 & $\begin{array}{l}1.62337 \\
6623\end{array}$ & 1.254271854 & CLCN3 \\
\hline axon (GO:0030424) & 0.464181054 & 1 & $\begin{array}{l}1.61186 \\
3314\end{array}$ & 1.237073825 & MAPT \\
\hline $\begin{array}{l}\text { RNA polymerase II } \\
\text { transcription factor } \\
\text { complex (GO:0090575) }\end{array}$ & 0.478271942 & 1 & $\begin{array}{l}1.54607 \\
2975\end{array}$ & 1.140345997 & GTF2H2C \\
\hline Iysosome (GO:0005764) & 0.557038143 & 1 & $\begin{array}{l}1.07712 \\
193\end{array}$ & 0.630247266 & DAGLB;ATP6V1D \\
\hline $\begin{array}{l}\text { Golgi membrane } \\
\text { (GO:0000139) }\end{array}$ & 0.582354922 & 1 & $\begin{array}{l}1.02838 \\
3381\end{array}$ & 0.556021375 & GALNT6;DSE \\
\hline $\begin{array}{l}\text { early endosome } \\
\text { (GO:0005769) }\end{array}$ & 0.626341943 & 1 & $\begin{array}{l}1.02375 \\
1024\end{array}$ & 0.478970947 & CLCN3 \\
\hline 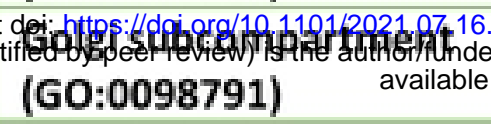 & 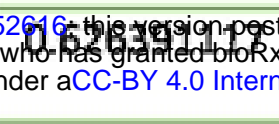 & JutV & 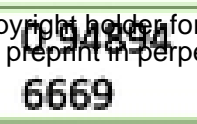 & 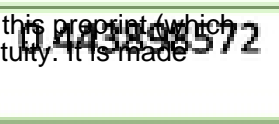 & GALNT6;DSE \\
\hline $\begin{array}{l}\text { mitochondrion } \\
\text { (GO:0005739) }\end{array}$ & 0.667382777 & 1 & $\begin{array}{l}0.88605 \\
3518\end{array}$ & 0.358312528 & TCHP;SUPV3L1;MAPT;CLU \\
\hline $\begin{array}{l}\text { mitochondrial matrix } \\
\text { (GO:0005759) }\end{array}$ & 0.745573163 & 1 & $\begin{array}{l}0.73789 \\
8465\end{array}$ & 0.216648473 & SUPV3L1 \\
\hline $\begin{array}{l}\text { secretory granule lumen } \\
\text { (GO:0034774) }\end{array}$ & 0.755626978 & 1 & $\begin{array}{l}0.71694 \\
8666\end{array}$ & 0.20089435 & $\mathrm{CLU}$ \\
\hline $\begin{array}{l}\text { integral component of } \\
\text { plasma membrane } \\
\text { (GO:0005887) }\end{array}$ & 0.96056947 & 1 & $\begin{array}{l}0.46604 \\
1136\end{array}$ & 0.018748356 & TFRC;NRG3;CLCN3 \\
\hline
\end{tabular}




\section{Supplemental Table 2 - Down-Regulated Genes by WT Tau}

\begin{tabular}{|c|c|c|c|c|c|}
\hline Term & P-value & $\begin{array}{l}\text { Adjusted P- } \\
\text { value }\end{array}$ & Odds Ratio & $\begin{array}{l}\text { Combined } \\
\text { Score }\end{array}$ & Genes \\
\hline $\begin{array}{l}\text { axon initial segment } \\
\text { (GO:0043194) }\end{array}$ & 0.013421829 & 1 & 74.07407407 & 319.3239135 & KCNQ2 \\
\hline $\begin{array}{l}\text { node of Ranvier } \\
\text { (GO:0033268) }\end{array}$ & 0.017856968 & 1 & 55.55555556 & 223.6311935 & KCNQ2 \\
\hline main axon (GO:0044304) & 0.048367756 & 1 & 20.2020202 & 61.19034096 & KCNQ2 \\
\hline $\begin{array}{l}\text { SCF ubiquitin ligase } \\
\text { complex (GO:0019005) }\end{array}$ & 0.077961385 & 1 & 12.34567901 & 31.50051407 & KLHL11 \\
\hline $\begin{array}{l}\text { coated vesicle } \\
\text { (GO:0030135) }\end{array}$ & 0.101264667 & 1 & 9.389671362 & 21.5025138 & STX6 \\
\hline ribosome (GO:0005840) & 0.108009525 & 1 & 8.771929825 & 19.52224439 & NCK1 \\
\hline perinuclear region of & 0.109697823 & 1 & 3.527336861 & 7.795505317 & STC2;STX6 \\
\hline \multicolumn{6}{|c|}{ 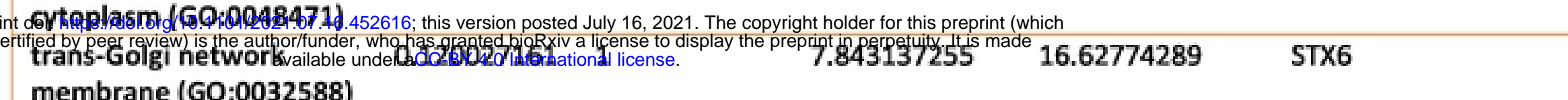 } \\
\hline $\begin{array}{l}\text { clathrin-coated vesicle } \\
\text { (GO:0030136) }\end{array}$ & 0.139709564 & 1 & 6.6666666667 & 13.1212637 & STX6 \\
\hline $\begin{array}{l}\text { Golgi membrane } \\
\text { (GO:0000139) }\end{array}$ & 0.141642689 & 1 & 3.016591252 & 5.895769726 & STX6;BLZF1 \\
\hline $\begin{array}{l}\text { Golgi subcompartment } \\
\text { (GO:0098791) }\end{array}$ & 0.160952725 & 1 & 2.783576896 & 5.084605682 & STX6;BLZF1 \\
\hline $\begin{array}{l}\text { mitochondrion } \\
\text { (GO:0005739) }\end{array}$ & 0.197703841 & 1 & 1.949317739 & 3.159815052 & TRUB1;OXCT1;PFDN2 \\
\hline $\begin{array}{l}\text { cullin-RING ubiquitin } \\
\text { ligase complex } \\
\text { (GO:0031461) }\end{array}$ & 0.238857152 & 1 & 3.683241252 & 5.273994836 & KLHL11 \\
\hline $\begin{array}{l}\text { trans-Golgi network } \\
\text { (GO:0005802) }\end{array}$ & 0.243455603 & 1 & 3.603603604 & 5.091245694 & STX6 \\
\hline nucleolus (GO:0005730) & 0.269438542 & 1 & 1.972386588 & 2.586617276 & UBE2T;UPF3A \\
\hline $\begin{array}{l}\text { early endosome } \\
\text { (GO:0005769) }\end{array}$ & 0.284737465 & 1 & 3.003003003 & 3.772335434 & STX6 \\
\hline $\begin{array}{l}\text { endoplasmic reticulum } \\
\text { lumen (GO:0005788) }\end{array}$ & 0.335058182 & 1 & 2.469135802 & 2.699879222 & STC2 \\
\hline $\begin{array}{l}\text { mitochondrial matrix } \\
\text { (GO:0005759) }\end{array}$ & 0.37245128 & 1 & 2.164502165 & 2.13776849 & OXCT1 \\
\hline $\begin{array}{l}\text { integral component of } \\
\text { plasma membrane } \\
\text { (GO:0005887) }\end{array}$ & 0.377736622 & 1 & 1.367053999 & 1.330906484 & $\begin{array}{l}\text { SLC26A2;KCNQ2;ICAM } \\
5\end{array}$ \\
\hline
\end{tabular}




\begin{tabular}{|c|c|c|c|c|c|}
\hline \multicolumn{6}{|c|}{ Supplemental Table 3. Up-Regulated Genes by P301L Tau } \\
\hline Term & P-value & $\begin{array}{l}\text { Adjusted P- } \\
\text { value }\end{array}$ & Odds Ratio & $\begin{array}{l}\text { Combined } \\
\text { Score }\end{array}$ & Genes \\
\hline axolemma (GO:0030673) & 0.002996578 & 1 & 333.3333333 & 1936.761417 & MAPT \\
\hline dendrite (GO:0030425) & 0.004890312 & 1 & 18.60465116 & 98.98603085 & NLGN1;MAPT \\
\hline filopodium tip (GO:0032433) & 0.004989818 & 0.741819593 & 200 & 1060.071173 & NLGN1 \\
\hline $\begin{array}{l}\text { spanning component of membrane } \\
\text { (GO:0089717) }\end{array}$ & 0.005487568 & 0.611863795 & 181.8181818 & 946.412758 & NLGN1 \\
\hline nuclear speck (GO:0016607) & 0.009082553 & 0.810163748 & 13.51351351 & 63.53243152 & ITPKC;MAPT \\
\hline $\begin{array}{l}\text { microtubule cytoskeleton } \\
\text { (GO:0015630) }\end{array}$ & 0.015239427 & 1 & 10.30927835 & 43.13267377 & FER;MAPT \\
\hline main axon (GO:0044304) & 0.016381548 & 1 & 60.60606061 & 249.1878617 & MAPT \\
\hline cytoskeleton (GO:0005856) & 0.026441482 & 1 & 7.692307692 & 27.94477859 & FER;MAPT \\
\hline \multicolumn{4}{|c|}{ 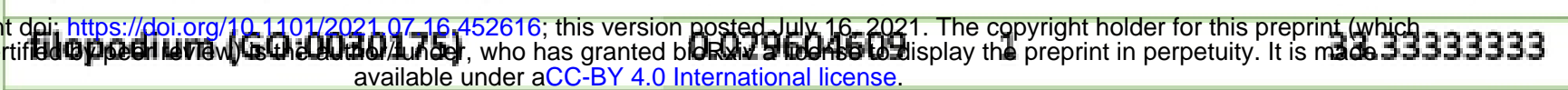 } & 117.3275068 & NLGN1 \\
\hline nuclear body (GO:0016604) & 0.036393121 & 1 & 6.472491909 & 21.44579618 & ITPKC;MAPT \\
\hline nuclear periphery (GO:0034399) & 0.038330884 & 1 & 25.64102564 & 83.62818815 & MAPT \\
\hline $\begin{array}{l}\text { ribonucleoprotein granule } \\
\text { (GO:0035770) }\end{array}$ & 0.039296097 & 1 & 25 & 80.91575164 & MAPT \\
\hline axon (GO:0030424) & 0.068319537 & 1 & 14.18439716 & 38.0646738 & MAPT \\
\hline $\begin{array}{l}\text { RNA polymerase II transcription } \\
\text { factor complex (GO:0090575) }\end{array}$ & 0.07113123 & 1 & 13.60544218 & 35.9622965 & FOS \\
\hline $\begin{array}{l}\text { cytoplasmic ribonucleoprotein } \\
\text { granule (GO:0036464) }\end{array}$ & 0.081838782 & 1 & 11.76470588 & 29.44710636 & MAPT \\
\hline microtubule (GO:0005874) & 0.100196316 & 1 & 9.523809524 & 21.91070345 & MAPT \\
\hline $\begin{array}{l}\text { polymeric cytoskeletal fiber } \\
\text { (GO:0099513) }\end{array}$ & 0.105186383 & 1 & 9.049773756 & 20.38028436 & MAPT \\
\hline nuclear chromatin (GO:0000790) & 0.119561652 & 1 & 7.90513834 & 16.78990615 & FER \\
\hline actin cytoskeleton (GO:0015629) & 0.137676093 & 1 & 6.802721088 & 13.48878577 & FER \\
\hline chromatin (GO:0000785) & 0.138551081 & 1 & 6.756756757 & 13.35483925 & FER \\
\hline $\begin{array}{l}\text { nuclear chromosome part } \\
\text { (GO:0044454) }\end{array}$ & 0.179622583 & 1 & 5.102040816 & 8.759680555 & FER \\
\hline nucleolus (GO:0005730) & 0.291015997 & 1 & 2.958579882 & 3.652003078 & TSPYL2 \\
\hline mitochondrion (GO:0005739) & 0.409477333 & 1 & 1.949317739 & 1.740494599 & MAPT \\
\hline $\begin{array}{l}\text { integral component of plasma } \\
\text { membrane (GO:0005887) }\end{array}$ & 0.532245452 & 1 & 1.367053999 & 0.862133316 & NLGN1 \\
\hline
\end{tabular}




\begin{tabular}{|llllll|}
\hline \multicolumn{2}{|c|}{ Supplemental Figure 4. Down-Regulated Genes by P301L Tau } & \\
\hline Term & P-value & Adjusted P-value & $\begin{array}{l}\text { Odds } \\
\text { Ratio }\end{array}$ & $\begin{array}{l}\text { Combined } \\
\text { Score }\end{array}$ & Genes \\
\hline $\begin{array}{l}\text { Cul4-RING E3 ubiquitin ligase complex } \\
\text { (GO:0080008) }\end{array}$ & 0.0018 & 0.80278471 & 555.5556 & 3511.104 & DCAF12 \\
\hline $\begin{array}{l}\text { cullin-RING ubiquitin ligase complex } \\
\text { (GO:0031461) }\end{array}$ & 0.00905 & 1 & 110.4972 & 519.8896 & DCAF12 \\
\hline centrosome (GO:0005813) & 0.02305 & 1 & 43.38395 & 163.5617 & DCAF12 \\
\hline microtubule organizing center (GO:0005815) & 0.02535 & 1 & 39.44773 & 144.9697 & DCAF12 \\
\hline
\end{tabular}

bioRxiv preprint doi: https://doi.org/10.1101/2021.07.16.452616; this version posted July 16, 2021. The copyright holder for this preprint (which was not certified by peer review) is the author/funder, who has granted bioRxiv a license to display the preprint in perpetuity. It is made 